\title{
Plate teCtonics AND CONTINENTAL BASALTIC GEOCHEMISTRY THROUGHOUT EARTH HISTORY
}

\author{
Preprint \\ C. Brenhin Keller ${ }^{1,2^{*}}$ and Blair Schoene ${ }^{3}$ \\ ${ }^{1}$ Berkeley Geochronology Center, Berkeley, CA 94709 \\ ${ }^{2}$ Department of Earth and Planetary Science, University of California, Berkeley, CA 94720 \\ ${ }^{3}$ Department of Geosciences, Guyot Hall, Princeton University, Princeton, NJ 08544
}

\begin{abstract}
Basaltic magmas constitute the primary mass flux from Earth's mantle to its crust, carrying information about the conditions of mantle melting through which they were generated. As such, changes in the average basaltic geochemistry through time reflect changes in underlying parameters such as mantle potential temperature and the geodynamic setting of mantle melting. However, sampling bias, preservation bias, and geological heterogeneity complicate the calculation of representative average compositions. Here we use weighted bootstrap resampling to minimize sampling bias over the heterogeneous rock record and obtain maximally representative average basaltic compositions through time. Over the approximately $4 \mathrm{Ga}$ of the continental rock record, the average composition of preserved continental basalts has evolved along a generally continuous trajectory, with decreasing compatible element concentrations and increasing incompatible element concentrations, punctuated by a comparatively rapid transition in some variables such as $\mathrm{La} / \mathrm{Yb}$ ratios and $\mathrm{Zr}, \mathrm{Nb}$, and $\mathrm{Ti}$ abundances approximately 2.5 Ga ago. Geochemical modelling of mantle melting systematics and trace element partitioning suggests that these observations can be explained by discontinuous changes in the mineralogy of mantle partial melting driven by a gradual decrease in mantle potential temperature, without appealing to any change in tectonic process. This interpretation is supported by the geochemical record of slab fluid input to continental basalts, which indicates no long-term change in the global proportion of arc versus non-arc basaltic magmatism at any time in the preserved rock record.
\end{abstract}

Systematic changes in crustal composition and magma chemistry between the Archean and the present have long been advanced on the basis of geochemical, petrological, and field observations. Differences between Archean and post-Archean crust - including the preponderance of granite-greenstone terranes, high-Na Trondhjemite-Tonalite-Granodiorite (TTG) plutons, and ultramafic komatiite lavas in the Archean - have led to much discussion about the style and rate of Archean tectonics (Green, 1975; Hargraves, 1976; Wilson et al., 1978; Sleep, 1992; de Wit, 1998; Hamilton, 1998; Bédard, 2006; Pease et al., 2008; Condie and Kröner, 2008; Stern, 2008). One interpretational paradigm invokes the abundance of TTGs, komatiites, and apparent lack of preserved blueschists and ophiolites in the Archean along with vertical tectonic interpretations of domeand-keel granite-greenstone terranes as evidence for a fundamentally different tectonic regime in the Archean (Hamilton, 1998; Bédard, 2006; Stern, 2008). In contrast, a more uniformitarian paradigm holds that qualitative differences between Archean and Proterozoic lithologies may be satisfactorily explained by secular changes in variables such as mantle temperature or water content in an essentially modern plate tectonic setting, backed by subduction-like geotherms and horizontal tectonic interpretations of, e.g., the Kaapvaal Craton and the $\mathrm{Su}-$ perior Province (Sleep, 1992; de Wit, 1998; Pease et al., 2008; Condie and Kröner, 2008).

Given conflicting structural models for Archean tectonics, some studies have instead used major and trace element geochemistry of Archean rocks to infer tectonic setting via mod- ern associations (e.g. Atherton and Petford, 1993; Martin et al., 2005). Such approaches have been stymied by two fundamental problems: (1) geochemical signatures are often nonunique and may not have the same genetic implications 4 Gyr ago as today, and (2) systematic temporal variations in geochemistry can be dwarfed by the variance of the rock record at any one time. The resulting uncertainties have limited our ability to apply modern chemotectonic signatures (e.g. Pearce and Cann, 1973) to the Archean.

To obtain meaningful temporal trends from the heterogeneous rock record, one productive approach has been to prioritize quality over quantity, for instance obtaining a well-constrained primitive magma composition by tracing a liquid line of descent from samples that have only fractionated olivine (Herzberg et al., 2010), or by focusing on the composition of carefully screened and geologically well-understood suites of samples Condie and O'Neill (2010); Condie et al. (2016). For instance, using 33 primary melt solutions culled from a dataset of 1500 "non-arc" basalt analyses, Herzberg (Herzberg et al., 2010) found primary magma temperatures consistent with a smooth trend in mantle potential temperature from $\sim 1530{ }^{\circ} \mathrm{C}$ in the Eoarchean to $\sim 1350{ }^{\circ} \mathrm{C}$ today, along a similar trend to the models of Korenaga (2008).

If, however, one obtains a sufficiently extensive, representative sample dataset, an alternative inclusive approach becomes possible. Given a perfectly representative sample set of the continental crust, the compositional average of this set has unique physical significance corresponding to the bulk composition of 

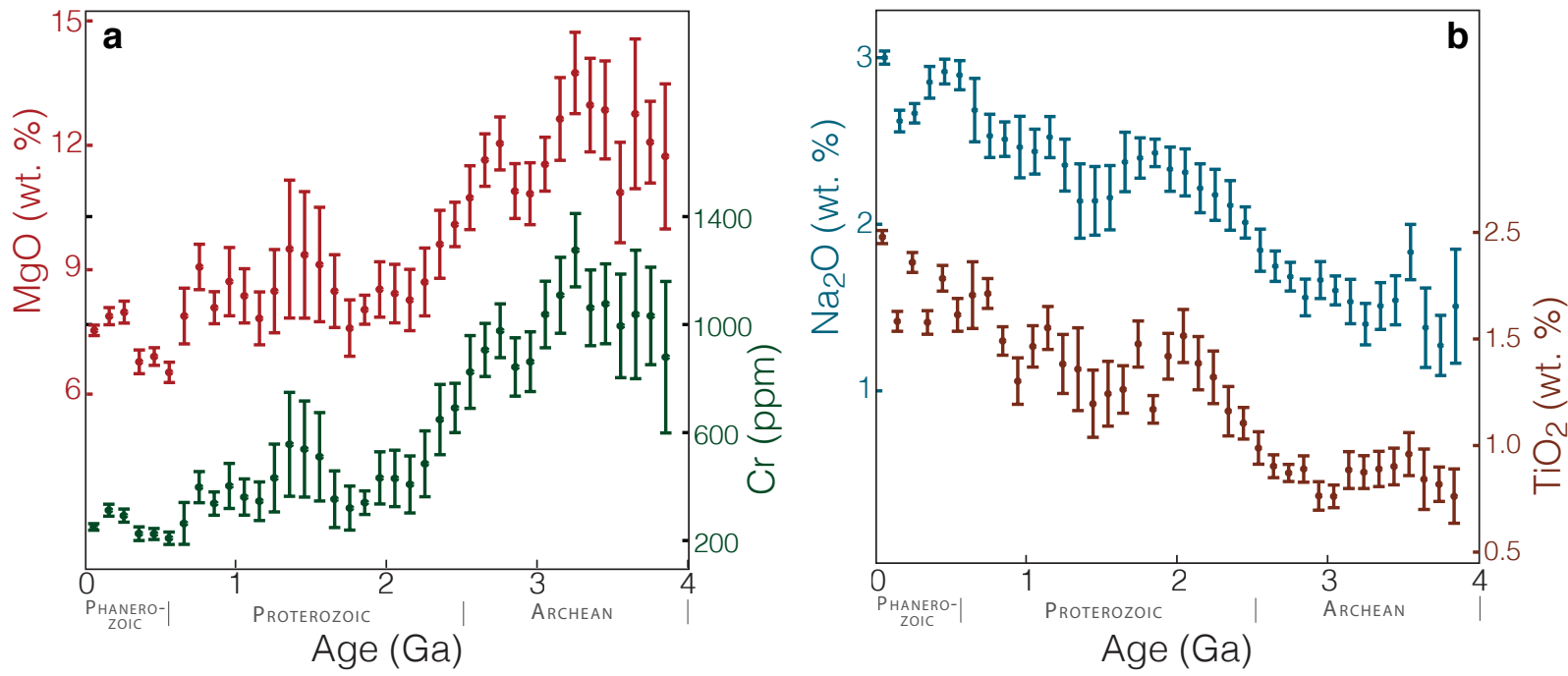

Figure 1: Secular evolution of compatible (a) and incompatible (b) element abundances in basalt over the past 4 Ga, following the methods of Keller and Schoene (2012)

the crust - that is, the composition that would result from physically homogenizing the entire crust. Consequently, changes in the average composition of new igneous crust contain information about the processes of crust formation: at long time scales, changes in the mean reflect secular variation in fundamental terrestrial parameters such as mantle potential temperature, crustal thickness, and tectonic mechanism of crust formation. A continuous temporal record of average crustal geochemistry would thus allow for the critical examination of temporal variations in such Earth system parameters and, consequently, the extrapolation of modern geologic processes back through Earth history in a conditional application of uniformitarianism. However, the quantification of systematic changes in mean crustal composition has been impeded by the difficulty of obtaining a representative sample population given the vast heterogeneity produced by magmatic processes, along with persistent questions about sampling and preservation bias Rudnick and Gao (2014).

Recently, increasing availability of large geochemical datasets, such as EarthChem, Georoc, and Navdat, has provided a new opportunity to quantify crustal composition by employing a greatly enlarged sample set. Our previous work (Keller and Schoene, 2012) has taken advantage of these freely-avaliable datasets to construct and analyze a $\sim 70,000$-sample whole-rock geochemical record of secular crustal evolution over the past $4 \mathrm{Ga}$, using weighted bootstrap resampling to obtain maximally representative temporal trends. First-order results revealed smooth decreases in compatible element abundance and increases in incompatible element abundance in basaltic samples (Figure 1), along with some indication of more discontinuous processes at the end of the Archean. While many indications of geochemical variation across the Archean-Proterozoic boundary were specific to the felsic record, changes in the estimated degree of average mantle melting and in basaltic $\mathrm{La} / \mathrm{Yb}$ ratio circa $2.5 \mathrm{Ga}$ suggested an analagous transition in the mafic record as well (Keller and Schoene, 2012).

Given the petrological complexities involved, previous work has not presented any definitive conclusions on the origin and significance of this potential transition in the mafic record.
However, many additional geochemical constraints are available due to the breadth of the underlying dataset. In order to better understand the implications of the new record of crustal evolution provided by statistical geochemistry, we focus here on the $\sim 30,000$-sample mafic subset of our database (defined as $43-51$ wt. $\% \mathrm{SiO}_{2}$, generally including komatiites but excluding many ultramafic cumulates), here termed basaltic sensu lato. As the product of $4 \mathrm{Ga}$ of partial mantle melting, this mafic record preserves the most direct account of mantle conditions through time, and provides the necessary foundation for any interpretation of subsequent processes of crustal differentiation. Our analysis of this record combines weighted bootstrap resampling with major- and trace-element geochemical modeling. This analysis allows us to study global variations in the process and setting of basaltic magma production over geologic time, in turn providing insight into the style and existence of plate tectonics throughout Earth history.

\section{Weighted Bootstrap Resampling}

In order to minimize sampling bias and accurately propagate temporal and compositional uncertainties to obtain an optimal estimate of the compositional distribution of Earth's exposed crust, we followed the weighted bootstrap resampling method of Keller and Schoene (2012), summarized in Appendix A and Supplementary Figures 1-6. As in our previous work, this technique was applied to a 70,000 -sample record of crustal whole-rock major and trace element geochemistry, including $\sim 67,000$ samples from the EarthChem repository, $\sim 2,500$ samples from Condie and O'Neill (2010), and 1500 from Moyen (2010) including age estimates and geospatial sample locations for each sample. Although outliers were not rejected categorically, the dataset was manually screened to identify suspicious data patterns and exclude any physically implausible data (e.g. concentrations $<0$ or $>100 \%$ ). We consider only samples collected from the present-day continental crust (i.e., excluding MORB and OIB except where naturally obducted), focusing unless otherwise noted on samples with between 43-51 wt. \% 
$\mathrm{SiO}_{2}$. This silica range is chosen to include a majority of mantle-derived mafic magmas (including komatiites), but exclude many ultramafic cumulates; however the exact basaltic silica range chosen has relatively little influence on the results (Supplementary Figure 6). To minimize filtering-induced interpretational circularity, no additional geochemical screening was conducted. The full dataset and all computational source code is available at https://github.com/brenhinkeller/ StatisticalGeochemistry under an MIT open-source license.

\section{Gradual SECULAR VARIATION IN CONTINENTAL BASALTIC COMPOSITION OVER EARTH HISTORY}

The results of this statistical analysis (Figures 1 - 6) reveal a diverse array of trends in average basaltic composition well beyond the two-standard-error level, ranging from smooth and continuous over $4 \mathrm{Gyr}$ to abrupt and discontinuous at the scale of our $100 \mathrm{Myr}$ binning resolution. Considering first the continuous trends, we observe what may be summarized as a consistent increase in incompatible element abundance accompanied by a decrease in compatible element abundance for average basalts and gabbros of a constant silica range $\left(43-51 \% \mathrm{SiO}_{2}\right)$ over the last $4 \mathrm{Ga}$. In addition to the observations of Keller and Schoene (Figure 1), such trends persist for a wide range of compatible and incompatible elements (Supplementary Figure 5), hinting at an igneous origin for these first-order variations.

\subsection{Sampling, preservation, and alteration}

In principle, systematic changes in average continental basalt composition may represent igneous variations in average crustal basaltic composition, secondary variations in the composition of preserved basalts due to increasing alteration or metamorphism of older samples, or illusory variations driven only by sampling or preservation bias. Evidence that variations in basaltic compatible and incompatible element abundances since $4 \mathrm{Ga}$ represent magmatic signatures, and are not overly influenced by alteration or weathering, is provided by the matching variations in element pairs with similar olivine/melt partition coefficients but with very distinct chemical properties. Figure 2 illustrates a number of such element pair ratios: $U$ and La, both highly incompatible but with dramatically different redox chemistry; $\mathrm{K}$ and $\mathrm{Sm}$, both incompatible but very distinct in abundance and aqueous fluid solubility; and $\mathrm{Sc}$ and $\mathrm{Co}$, both compatible but with distinct size, charge, and redox chemistry. Differences in ionic radius, charge, and redox chemistry will greatly influence elemental mobility and solubility during alteration and metasomatism, yet all ratios remain nearly invariant over the last $4 \mathrm{Ga}$.

Further, while sampling and preservation bias are difficult to eliminate even with our weighted bootstrap resampling methods (Appendix A), there is no known a priori reason that either sampling or preservation bias should favor more mafic compositions in the past and more felsic compositions towards the present. While difficult to quantify given its dependence on the collective sampling behavior of the geological community, the expected distribution of sampling bias in silica space is likely to disproportionately favor less common rock types - acting counter to any underlying changes in lithology. Meanwhile,

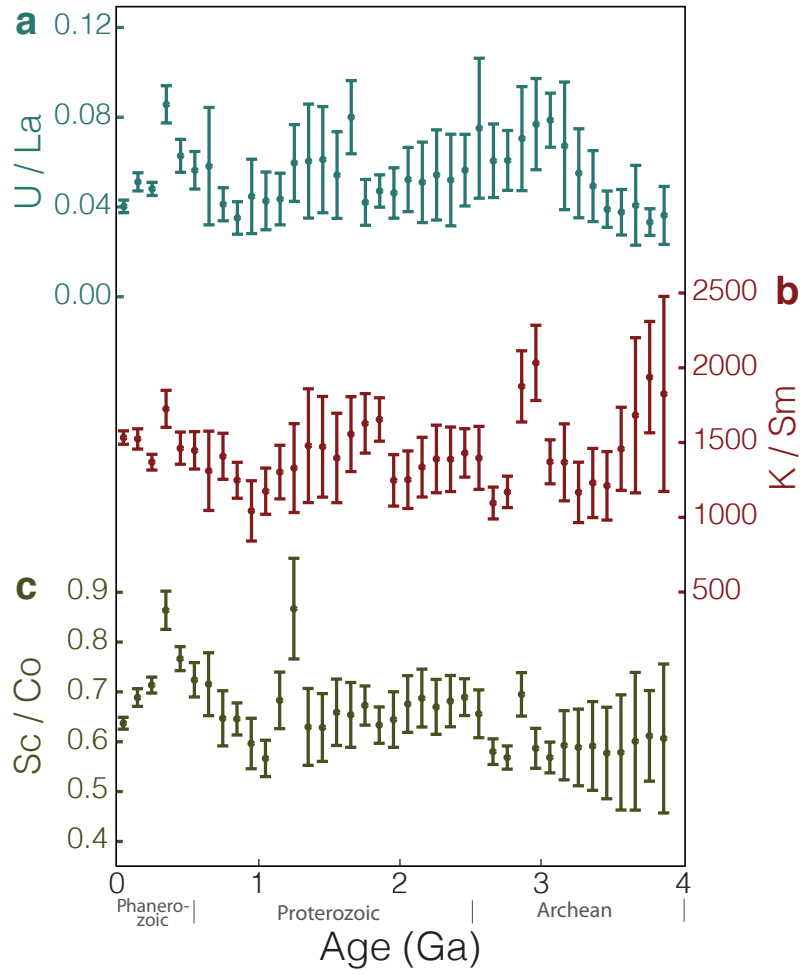

Figure 2: Ratios of major and trace elements with similar olivine/melt partition coefficients but dramatically different chemical properties during weathering and alteration, showing broad invariance over time. (a) Uranium / Lanthanum, both highly incompatible. (b) Potassium / Samarium, both incompatible. (c) Scandium / Cobalt, both compatible. Here and throughout, ratios are calculated using the method of Keller and Schoene (2012), starting with fractions $a /(a+b)$ (to avoid numerical instability) for each whole-rock analysis with both elements defined, then resampled and averaged before converting back ratio space $a / b$.

preservation bias should favor (if anything) more felsic samples over time, given the increased chemical weathering rate and greater density of mafic rocks, which make mafic crust more vulnerable both to erosional loss at the surface and convective loss at the base of the crust.

\subsection{Variation in the extent of mantle melting}

Given an igneous interpretation, the most straightforward hypothesis to produce the systematic temporal trends in basaltic compatible and incompatible element abundance observed by Keller and Schoene (2012) is that secular mantle cooling has decreased the average extent of mantle partial melting through time, resulting in increasing incompatible element concentrations and decreasing compatible element concentrations as seen in Figure 1. However, a range of confounding factors could bias these trends, including changes in mantle depletion, basaltic magma differentiation, and magma water content.

\subsubsection{Mantle depletion}

Since Earth's mantle forms the depleted complement to the silicic continental crust, the mantle has become depleted in incompatible elements as a result of crust formation (Hofmann, 

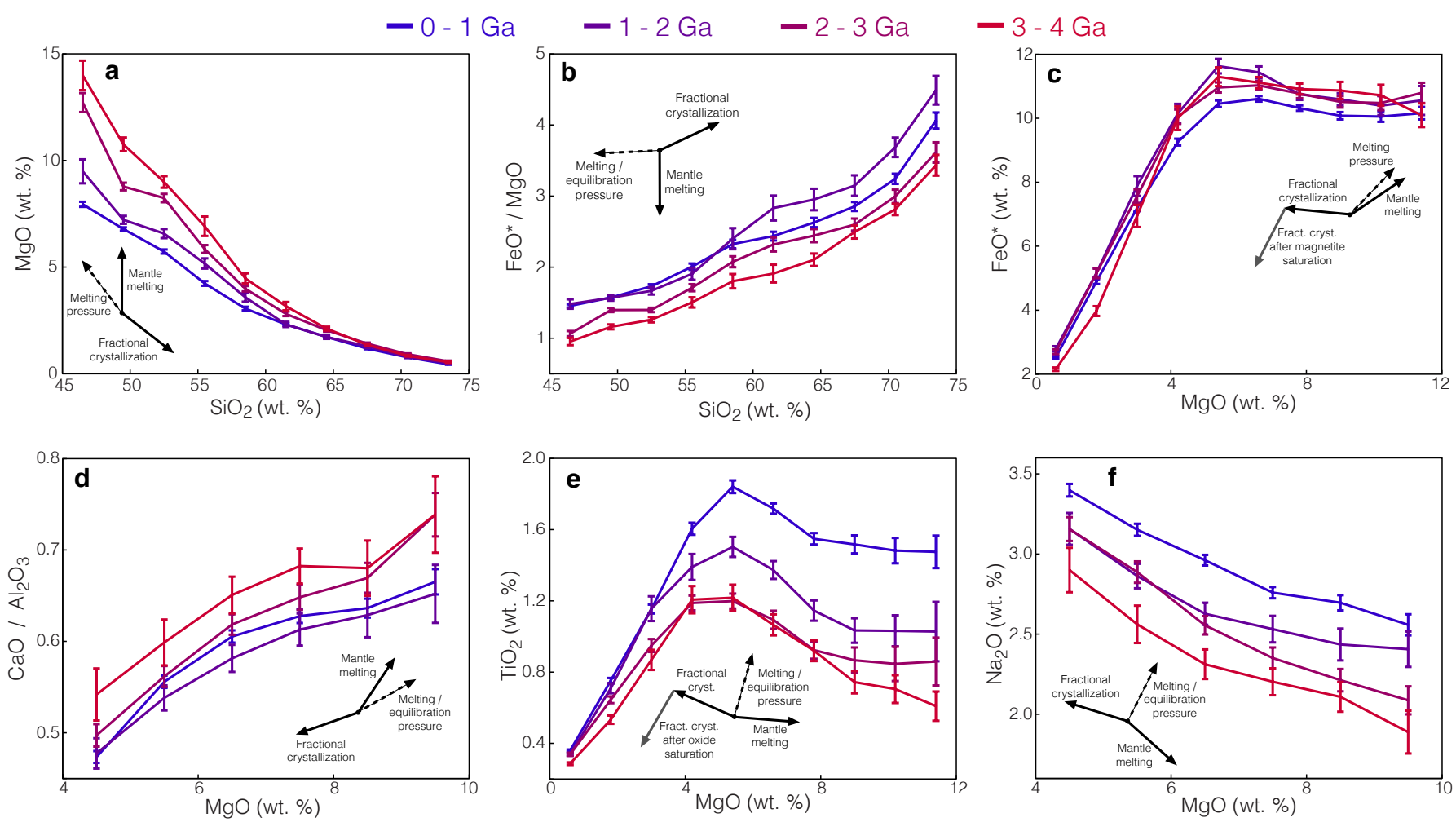

Figure 3: Deconvolving the effects of mantle melting and fractional crystallization. Observed trends throughout this figure were produced by binning the full dataset of Keller and Schoene (2012) - by $\mathrm{SiO}_{2}$ in $\mathbf{a}-\mathbf{b}$ and by $\mathbf{M g O}$ in $\mathbf{c}-\mathbf{f}$. Independent variable uncertainties are smaller than the symbol size, with binning ranges chosen to illustrate a region of petrologic interest in each subfigure; full methodology is described in the text. (a) $\mathrm{MgO}$ decreases as a function of silica content during fractional crystallization, converging at high $\mathrm{SiO}_{2}$. Reductions in mantle melting over the the last $4 \mathrm{Ga}$ decrease $\mathrm{MgO}$ at nearly constant silica, producing offsets between different age differentiation trends at high angle to the differentiation trend. (b) $\mathrm{FeO} * \mathrm{MgO}$ ratio increases with silica during fractional crystallization, but decreases at nearly constant silica during partial melting, producing systematic offsets between fractionation trends of different ages that cannot be explained by changes in basalt differentiation. $\mathrm{FeO}^{*}$ represents total $\mathrm{Fe}^{2+}+\mathrm{Fe}^{3+}$ normalized as $\mathrm{FeO}$. (c) Relative effects of partial melting and fractional crystallization on $\mathrm{FeO}^{*}$ as a function of $\mathrm{MgO}$. (d) Changes in mantle partial melting and basalt fractional crystallization have distinct slopes in $\mathrm{CaO} / \mathrm{Al}_{2} \mathrm{O}_{3}-$ $\mathrm{MgO}$ space, producing resolvable offsets in differentiation trends over time. (e) The systematic offset between $\mathrm{Archean}$ and modern $\mathrm{MgO}_{\mathrm{O}} \mathrm{TiO}{ }_{2}$ differentiation trends is not well explained by changes in either extent of mantle melting or fractional crystallization, but may instead reflect systematic changes in depth of mantle melting or reequilibration. (f) Similar offsets between Archean and later $\mathrm{MgO}_{-} \mathrm{Na}_{2} \mathrm{O}$ differentiation trends again suggest systematic variation in melting and/or equilibration pressure over the past $4 \mathrm{Ga}$. Notably, Archean basalts have lower $\mathrm{Na}_{2} \mathrm{O}$ for a given $\mathrm{MgO}$, despite the well-known high $\mathrm{Na}$ signatures of Archean granitoids.

1997). While terrestrial crustal growth rates remain actively debated, nearly all models agree that the crust has either grown or remained constant in volume since the end of the Hadean Harrison (2009). Constant or increasing crustal volume would result in either constant or increasingly depleted mantle composition. Any increase in mantle depletion would not, however, explain the observed trends: an increasingly depleted mantle would result in decreasing incompatible element concentrations in basalts over time, opposite the trends observed from our dataset.

\subsubsection{Differentiation}

A more subtle point concerns the possibility for changes in the extent or character of basaltic magma differentiation. For many elements, increasing magma differentiation by fractional crystallization and decreasing degree of primary mantle melting produce similar changes in elemental abundance. As a result, differentiating the contributions of these two processes can be problematic. In order to resolve such processes, we turn to a variety of differentiation diagrams featuring elements or ratios that behave differently during mantle partial melting as opposed to basalt fractional crystallization (Figure 3).

It is important to note that the differentiation trends shown in Figure 3 are not liquid lines of descent, but rather the average of many discrete lines of descent from different magmas under different conditions. As such, the interpretation is distinct from a traditional liquid line of descent. Nonetheless, changes in the average extent of mantle melting or average trend of differentiation will remain clearly visible. Due to the heterogeneity of mantle-derived basalt compositions, a single "primitive" origin is not shown, but in general mantle-derived basalts will originate on the left and differentiate to the right in Figure 3a-b, and originate on the right and differentiate to the left in $3 \mathbf{c}-\mathbf{f}$, as illustrated by the schematic "fractional crystallization" arrows. The directions of the accompanying mantle "melting extent" and mantle "melting pressure" were established by pMELTS- 

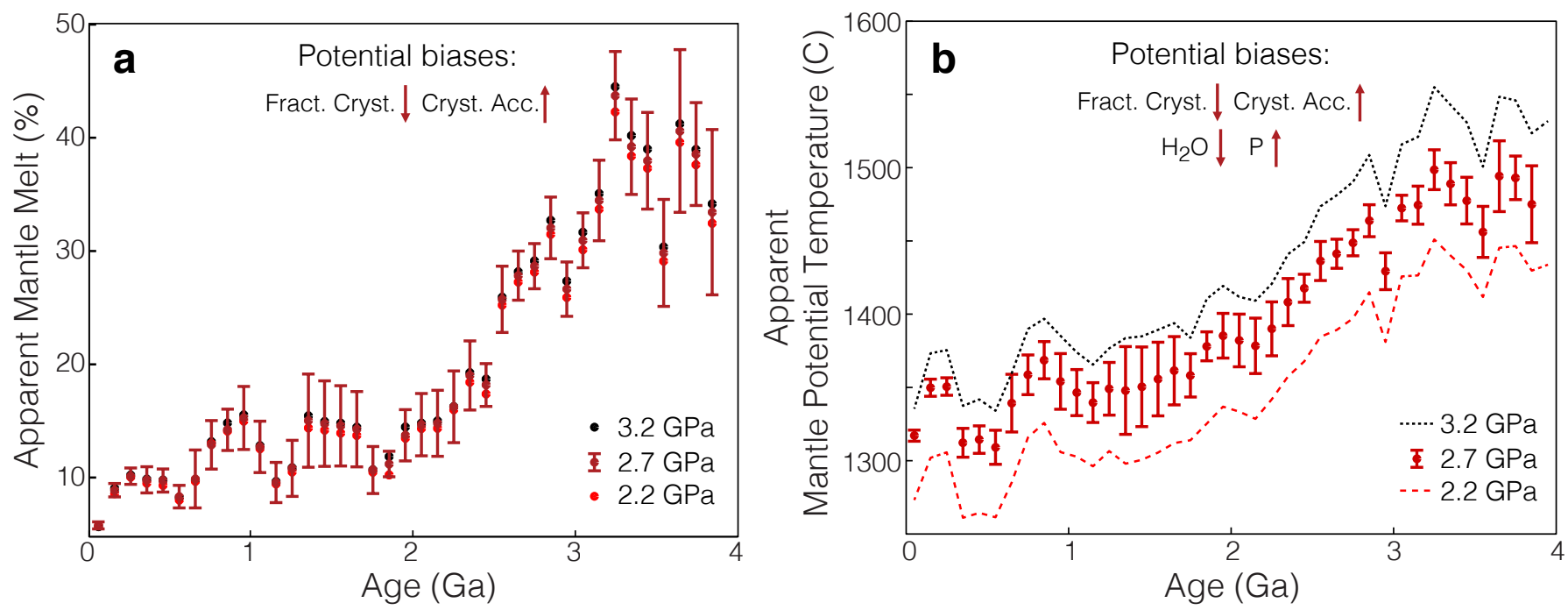

Figure 4: Estimated average extent of mantle melting (a) and mantle potential temperature (b) through time, determined by least-squares comparison of observed major element concentrations for each basaltic sample in the database $\left(43-54 \% \mathrm{SiO}_{2}\right)$ to those of calculated basalt compositions corresponding to 0 to $100 \%$ partial melting of primitive mantle. Mantle melting was simulated by pMELTS-mode alphaMELTS isobaric equilibrium batch melting calculations (Ghiorso et al., 2002; Asimow et al., 2004; Smith and Asimow, 2005) using the primitive mantle composition of McDonough (McDonough and Sun, 1995) with 0.15 wt.\% initial $\mathrm{H}_{2} \mathrm{O}$ at 2.2, 2.7 and 3.2 GPa. Compared to a record derived from oceanic basalts, this continental basaltic record is less directly representative of the freely convecting mantle, influenced by, e.g., conditions in the arc mantle wedge.

mode alphaMELTS simulations (Ghiorso et al., 2002; Asimow et al., 2004; Smith and Asimow, 2005) of isobaric batch mantle melting from solidus to liquidus at a range of pressures between 1 and $3 \mathrm{GPa}$ using the primitive mantle composition of McDonough (McDonough and Sun, 1995) with varying bulk mantle water contents between $0.1 \%$ and $1 \% \mathrm{H}_{2} \mathrm{O}$ (Appendix B; Supplementary Figure 7). Variation in water content over this range resulted in substantial differences in primitive magma composition for some elements, but neither varying water content nor varying oxygen fugacity substantially changes the overall vector of mantle melting extent and melting pressure at the scale of the schematic effect vectors.

As seen in Figure 3, differentiation trends for successive 1Gyr periods of Earth history define parallel arrays, indicating changes in mantle partial melt composition perpendicular (in elemental cross-plot space) to the prevailing differentiation trend (c.f. Klein and Langmuir, 1987). In particular, changing degree of mantle melt appears to have little effect on primary magma silica content relative to other major elements such as $\mathrm{MgO}$ (e.g., Supplementary Figure 7), such that binning basaltic magmas by silica serves as a relatively robust way to extract the effects of mantle partial melting for magmas which have undergone similar degrees of differentiation (Figure 3 ).

\subsubsection{Water content}

Ruling out changes in mantle depletion or basaltic differentiation, a final caveat stems from the ability of water to decrease mantle solidus temperature (e.g. Mysen and Boettcher, 1975; Grove et al., 2006). Decreasing mantle water content could in principle lead to decreasing mantle melting extent for a constant potential temperature, with solidus temperature increasing in response to ongoing mantle degassing. However, changing mantle water content also has major predictions for subsequent magma differentiation. Notably, increased magmatic water activity promotes magnetite saturation relative to the major rockforming silicate minerals, changing magma $\mathrm{Fe} / \mathrm{Mg}$ ratios during differentiation (Sisson and Grove, 1993; Botcharnikov et al., 2008). As demonstrated in Figure 3b-c, neither the $\mathrm{FeO} * / \mathrm{MgO}^{*}$ slope during differentiation nor the relative occurrence of magnetite saturation in $\mathrm{FeO}^{*}-\mathrm{MgO}$ space is significantly altered over the past $4 \mathrm{Ga}$. Consequently, declining extent of mantle melting in response to secular mantle cooling remains the simplest explanation for the observed first-order variations in average basaltic geochemistry through time.

\subsubsection{Melting extent}

If it is possible to calculate the approximate extent of mantle melting for each basaltic sample in the database, we may use this information to produce a temporal record of global average mantle melting extent. Along these lines, one firstorder methodology is to compare the major element composition of each whole-rock sample to pMELTS simulations of primitive mantle melting and find the (least-squares) best-fit extent of mantle melting for each basaltic sample. A representative average record through time is then produced by the usual weighted bootstrap resampling technique (Keller and Schoene, 2012). This approach naturally produces a corresponding estimate of mantle melting temperature for each sample, allowing for the calculation of apparent mantle potential temperature through time. This first-order approach makes no attempt to either exclude basaltic samples that have undergone small degrees of fractional crystallization or crystal accumulation, or to numerically correct back to a primitive magma composition. Since most basaltic magmas have undergone some degree of 
fractional crystallization, this approach likely results in an underestimation of mantle melting extent. However, in the absence of changes in degree of fractional crystallization through time, this underestimation results in only a systematic offset with little influence on relative temporal trends.

\subsubsection{Mantle potential temperature}

The results (Figure 4) are recalculated using this approach for isobaric batch melting at pressures between 2.2 and $3.2 \mathrm{GPa}$ using the primitive mantle composition of McDonough (McDonough and Sun, 1995) with 0.15 wt.\% initial $\mathrm{H}_{2} \mathrm{O}$. Percent melt estimates display a clear decrease from nearly $40 \%$ mantle melting in the Archean to $\sim 10 \%$ today, in agreement with independent estimates of modern and Archean mantle melting (Kelley et al., 2010; Portnyagin et al., 2007; Walter, 1998; Bernstein et al., 2007) despite the lack of a fractionation correction. Over the same time period, the corresponding mantle potential temperature record cooled from approximately $1500^{\circ} \mathrm{C}$ in the Archean to $1330{ }^{\circ} \mathrm{C}$ at present, following a trend intermediate between the models of Korenaga (Korenaga, 2008) and Davies (Davies, 2009), which are based on scaling laws for the mantle heat budget through time. Although average basaltic water content appears not to have changed substantially over the past $4 \mathrm{Ga}$ (no change in $\mathrm{FeO} * / \mathrm{MgO}$ differentiation slope in Figure 3b-c, discussed further in section 4.1), the same cannot be said for mantle melting pressure; systematic offsets in $\mathrm{MgO}-\mathrm{TiO}_{2}$ and $\mathrm{MgO}-\mathrm{Na}_{2} \mathrm{O}$ differentiation trends (Figure 3e-f) likely require systematic variation in melting, equilibration or differentiation pressure; a naive comparison to MELTS simulations would suggest increasing average mantle melting pressure through time, though this inference is not definitive. If present, a systematic increase in mantle melting pressure would allow a smaller range of mantle cooling to explain the observed decrease in mantle melting extent. Nonetheless, the total magnitude of average mantle cooling $\left(\sim 170{ }^{\circ} \mathrm{C}\right)$ is generally intermediate between those suggested by Grove and Parman (2004) and Herzberg et al. (2010), and broadly consistent with previous estimates despite contrasting methodology (Herzberg et al., 2010; Condie et al., 2016).

By examining basalts preserved in the continental crust, we are largely excluding oceanic basalts such as MORB and OIB. Instead, considering the results of Section 4.1, the temperature trends of Figure 4 are arguably most comparable to the hydrated mantle basalt estimates of Condie et al. (2016). However, in many other ways the results display only limited sensitivity to model assumptions. Varying the sample set by rejecting samples with komatiitic $\mathrm{MgO}$ contents only slightly diminishes estimated temperatures and melting extents (Supplementary Figure 8), since excluding komatiites has little effect on most major elements other than $\mathrm{MgO}$. Excluding samples with high least-squares residuals similarly has little effect on the results (Supplementary Figure 9). An equivalent model employing continuous polybaric fractional melting in place of isobaric batch melting (Supplementary Figure 10) results in higher estimated potential temperature due to rapid removal of any initial water during fractional melting, but has almost no impact on estimated melting extent. Overall, relative trends are broadly consistent for a wide range of melting models, and while absolute mantle potential temperature estimates are necessarily model-

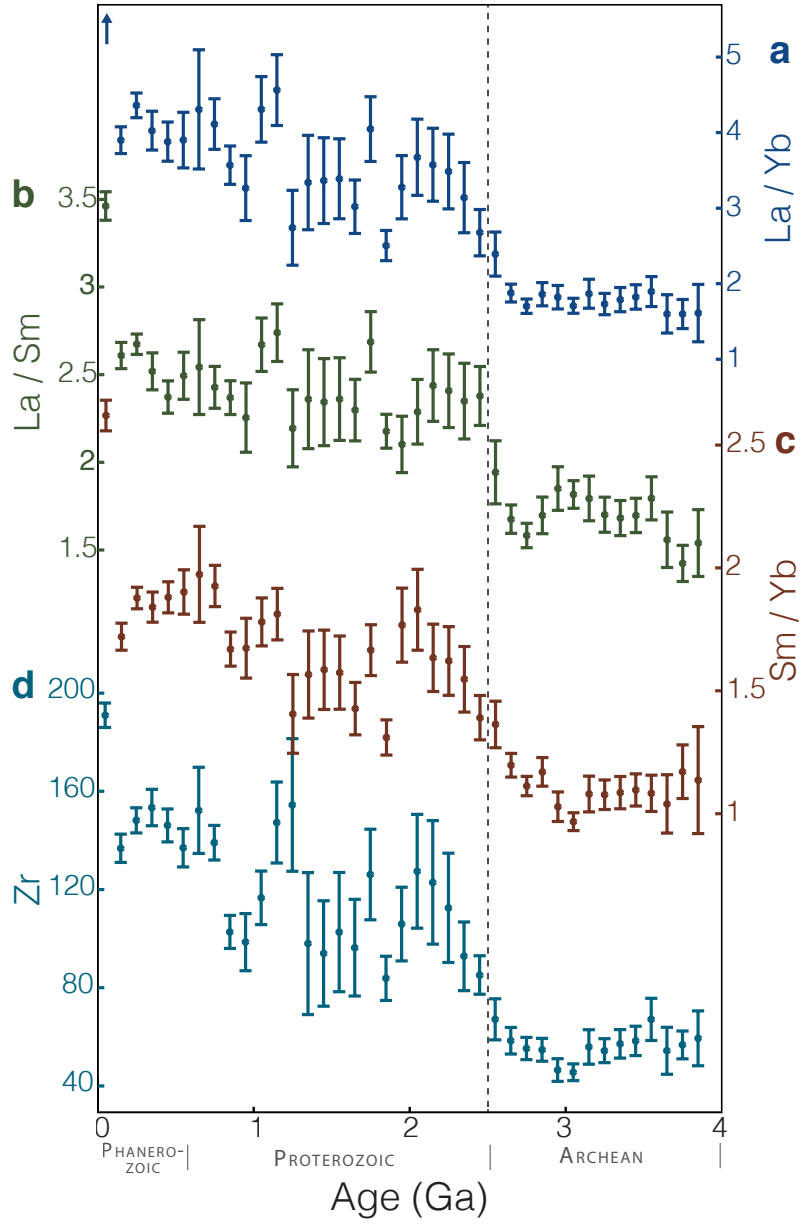

Figure 5: Basaltic trace elements and ratios showing rapid ( $<1 \mathrm{Gyr})$ changes near the end of the Archean. (a-c): increasing rare earth fractionation, including light/heavy $(\mathrm{La} / \mathrm{Yb}$; a), light/middle $(\mathrm{La} / \mathrm{Sm}$; b), and middle/heavy $(\mathrm{Sm} / \mathrm{Yb}$; c) rare earth element enrichment. (d): Basaltic $\mathrm{Zr}$ abundance.

dependent, estimated mantle melting extents are much less so (Supplementary Figure 11; Appendix B).

\section{RAPID GEOCHEMICAL VARIATION AT THE END OF THE ARCHEAN}

While the estimated decreases in melting temperature generally follow a smooth curve over the past $4 \mathrm{Ga}$, a marked offset (at the two-standard-error level) is observed in average apparent mantle percent melt across the Archean/Proterozoic boundary at $2.5 \mathrm{Ga}$ (Figure $4 \mathrm{a}$ ). The absence of any similarly rapid shift in the corresponding temperature record (consistent with the thermal inertia of the mantle) suggests that, if representative of a real phenomenon, this offset does not stem directly from a change in mantle temperature alone, but rather from a systematic threshold in process, mineralogy, or rate.

In addition to the mantle melting extent record in Figure 4a, a number of basaltic trace element abundances and ratios also exhibit shifts at or near the Archean-Proterozoic boundary. This effect was first observed for $\mathrm{La} / \mathrm{Yb}$ ratio, where trace element calculations indicate that the increase in average basaltic $\mathrm{La} / \mathrm{Yb}$ 


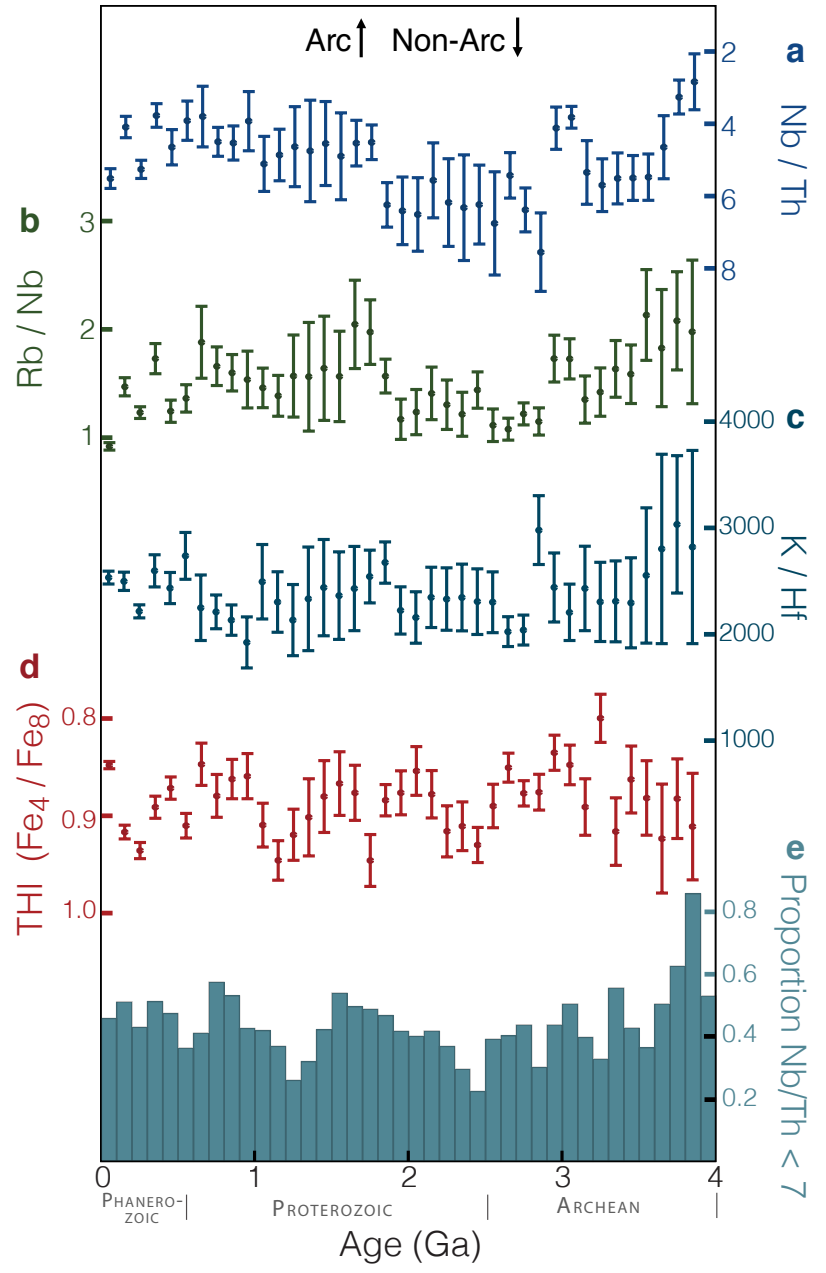

Figure 6: Constancy of arc vs. non-arc geochemical signatures in basalts over time. (a): Basaltic $\mathrm{Nb} / \mathrm{Th}$ ratio. (b): Basaltic $\mathrm{Rb} / \mathrm{Nb}$ ratio. (c): Tholeiitic Index (THI) (Zimmer et al., 2010)- $\mathrm{FeO}^{*}$ for samples 4 wt. $\% \mathrm{MgO}$ divided by $\mathrm{FeO}^{*}$ for samples 8 wt. $\% \mathrm{MgO}$ (d): Proportion of basaltic samples with "arc-like" $\mathrm{Nb} / \mathrm{Th}$. Ratios are calculated as in Figure 2, while Tholeiitic index is calculated using bins of $4 \pm 0.5$ and $8 \pm 0.5$ wt. $\% \mathrm{MgO}$

at the end of the Archean cannot be explained by changes in percent mantle melting alone without either a change in partition coefficients or source composition (Keller and Schoene, 2012). As seen in Figure 5a-c, broadly step-like increases in rare earth fractionation (for both light/middle and middle/heavy rare earth elements) are demonstrated by average basaltic $\mathrm{La} / \mathrm{Yb}, \mathrm{La} / \mathrm{Sm}$, and $\mathrm{Sm} / \mathrm{Yb}$ ratios. Similarly rapid $(<1 \mathrm{Gyr})$ transitions are observed in the abundance of a number of incompatible high-fieldstrength elements such as $\mathrm{Zr}$ (Figure 5d) and Ti.

\subsection{Geochemical signatures of subduction}

One potential model for the observed $2.5 \mathrm{Ga}$ transition involves the initiation of modern-style subduction at the end of the Archean, which could increase average basaltic $\mathrm{La} / \mathrm{Yb}, \mathrm{La} / \mathrm{Sm}$, and $\mathrm{Sm} / \mathrm{Yb}$ by addition of high $\mathrm{La} / \mathrm{Yb}$ slab fluids and subducted sediment. It has been suggested that such a scenario could also produce a decrease in apparent degree of mantle melting due to the introduction of cold subducted slabs into the mantle (Condie and O'Neill, 2010). If this is the case, the same basaltic samples should also record a dramatic change in subduction signatures which record the effect of slab fluids due to the relative insolubility of high field strength elements such as $\mathrm{Nb}$ and $\mathrm{Ta}$ compared to large ion lithophiles like $\mathrm{K}$ and $\mathrm{Rb}$.

In particular, Condie and O'Neill (2010) suggested the use of the $\mathrm{Nb} / \mathrm{Th}$ ratio, which unlike many other high field strength/large ion lithophile ratios is relatively insensitive to changing percent melt due to the similar incompatibility of $\mathrm{Nb}$ and $\mathrm{Th}$ in the mantle. In particular, $\mathrm{Nb} / \mathrm{Th}$ ratios below 5 are generally associated with a subduction setting, where slab fluids are abundant, while $\mathrm{Nb} / \mathrm{Th}$ ratios above 7 are associated with melts produced in the absence of slab fluids. However, as seen in Figure 6, both the average $\mathrm{Nb} / \mathrm{Th}$ and the percentage of high- and low- $\mathrm{Nb} / \mathrm{Th}$ continental basalts are essentially constant throughout recorded Earth history. Alternative subduction signatures such as $\mathrm{K} / \mathrm{Hf}$ and $\mathrm{Rb} / \mathrm{Nb}$ - also with matching peridotite/melt partition coefficients but with even higher solubility contrast (Tatsumi et al., 1986) — similarly show no major discontinuity across the Archean-Proterozoic boundary and no clear trend over geologic time (Figure 6b-c).

Further insight into the prevalence of subduction throughout geologic time is provided by the record of calc-alkaline vs. tholeiitic magma series. More hydrous and more oxidized magmas saturate Fe-Mg oxides such as magnetite and ilmenite sooner relative to the major rock-forming silicate minerals, driving the remaining magma composition away from the Fe axis and resulting in a calc-alkaline differentiation trend (Sisson and Grove, 1993; Botcharnikov et al., 2008). Consequently, calcalkaline differentiation is observed to correlate strongly with magmatic water content (Zimmer et al., 2010). While tholeiitic magmas may occur in multiple tectonic settings, the calcalkaline series is restricted almost exclusively to subduction zones, where it is a dominant differentiation trend. Consequently, the initiation of subduction in the rock record should coincide with an increase in the abundance of the calc-alkaline series.

Quantitatively, Zimmer et al. (2010) have proposed the "tholeiitic index" as a numerical measure for the degree of tholeiitic vs. calc-alkaline differentiation in a given magma series, defined as total $\mathrm{Fe}$ at $4 \% \mathrm{MgO}$ over total $\mathrm{Fe}$ at $8 \% \mathrm{MgO}$ for magmas of the same series (e.g. as in Figure 3c). Extending this metric to consider the average tholeiitic index of the continental crust - comparing the FeO content of magmas with 4 wt.\% $\mathrm{MgO}$ to those with 8 wt. $\% \mathrm{MgO}$ for each $100 \mathrm{Ma}$ time bin should allow us to discern systematic changes in the abundance of calc-alkaline versus tholeiitic differentiation. Remarkably, as seen in Figure 6d, the average tholeiitic index of juvenile basalts have remained constant over the last $\sim 3.8 \mathrm{Ga}$, strongly suggesting that average continental basaltic water content has remained relatively constant for most of Earth history. These results, including an average THI of $\sim 0.9$ are consistent with the predominantly calc-alkaline average differentiation trends observed in Figure 3b-c.

\subsection{Trace element modelling}

If tectonic setting and magma water activity are constant over the last $\sim 4 \mathrm{Ga}$, one possible remaining source of discontinuous threshold processes in the basaltic record involves melting sys- 

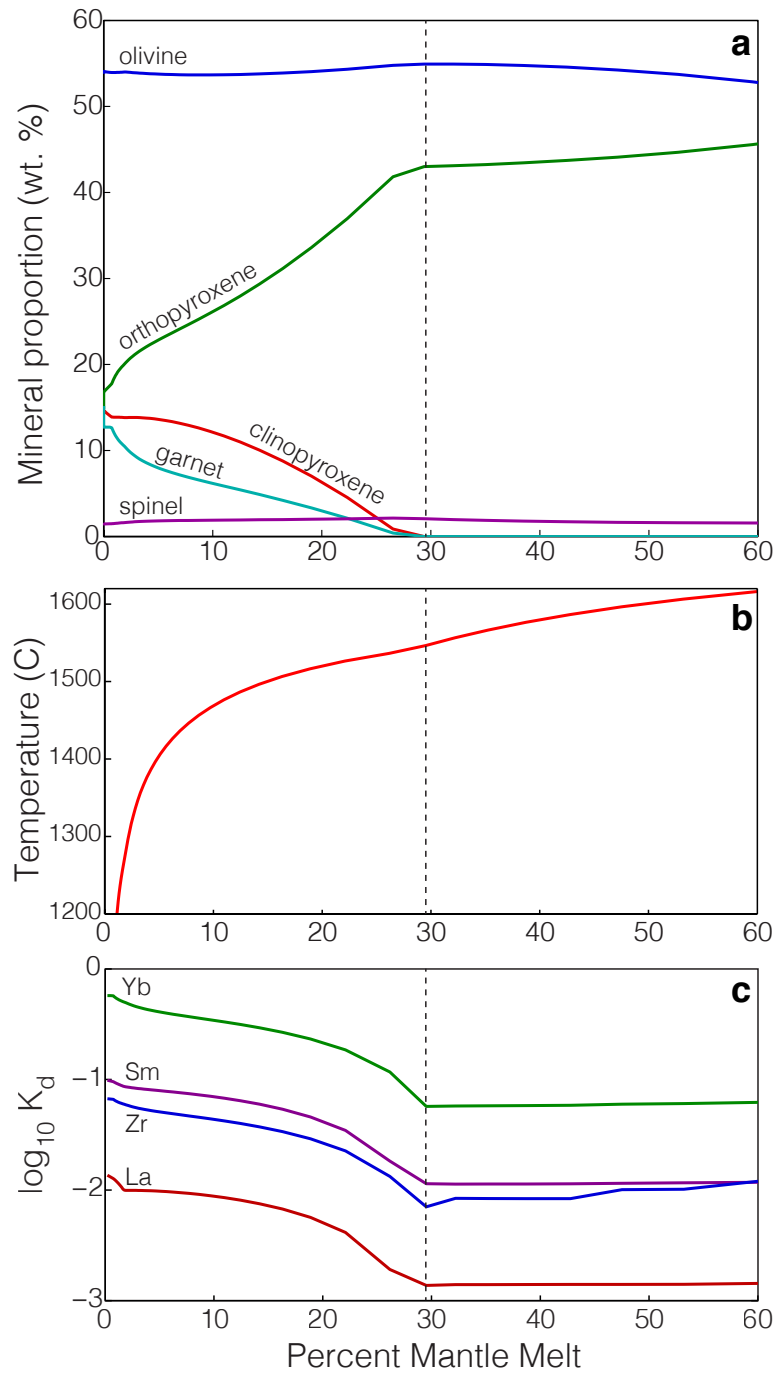

Figure 7: Mantle melting sytematics as modeled by pMELTS as a function of melting extent at $2.7 \mathrm{GPa}$. (a): Modal mineral abundances as a weight percentage of the remaining solid. (b): Mantle melting temperature as a function of melting extent, displaying strong nonlinearity. (c): Peridotite/melt partition coefficients based on mineral percentages from (a) and GERM mineral/melt partition coefficients

tematics - the modal mineralogy of the residual mantle as a function of melt extraction. Although our earlier results suggested that the observed $\mathrm{La} / \mathrm{Yb}$ trends could not be fit with a constant set of partition coefficients (Keller and Schoene, 2012), bulk peridotite/melt partition coefficients are not constant during mantle melting, nor is melt productivity linear as a function of mantle temperature. Instead, as is well known from both experimental and theoretical studies, the relationship of mantle percent melt to melting temperature is markedly non-linear, with discontinuities in slope corresponding to the exhaustion of peridotite minerals upon progressive melting, most notably at the point of clinopyroxene exhaustion around $25-30 \%$ melt (Herzberg and Zhang, 1996; Hirschmann et al., 1998).

In order to investigate the effects of mantle melting systematics on melt productivity and partition coefficients, we paired the pMELTS mantle melting simulations from Section 3.2 with

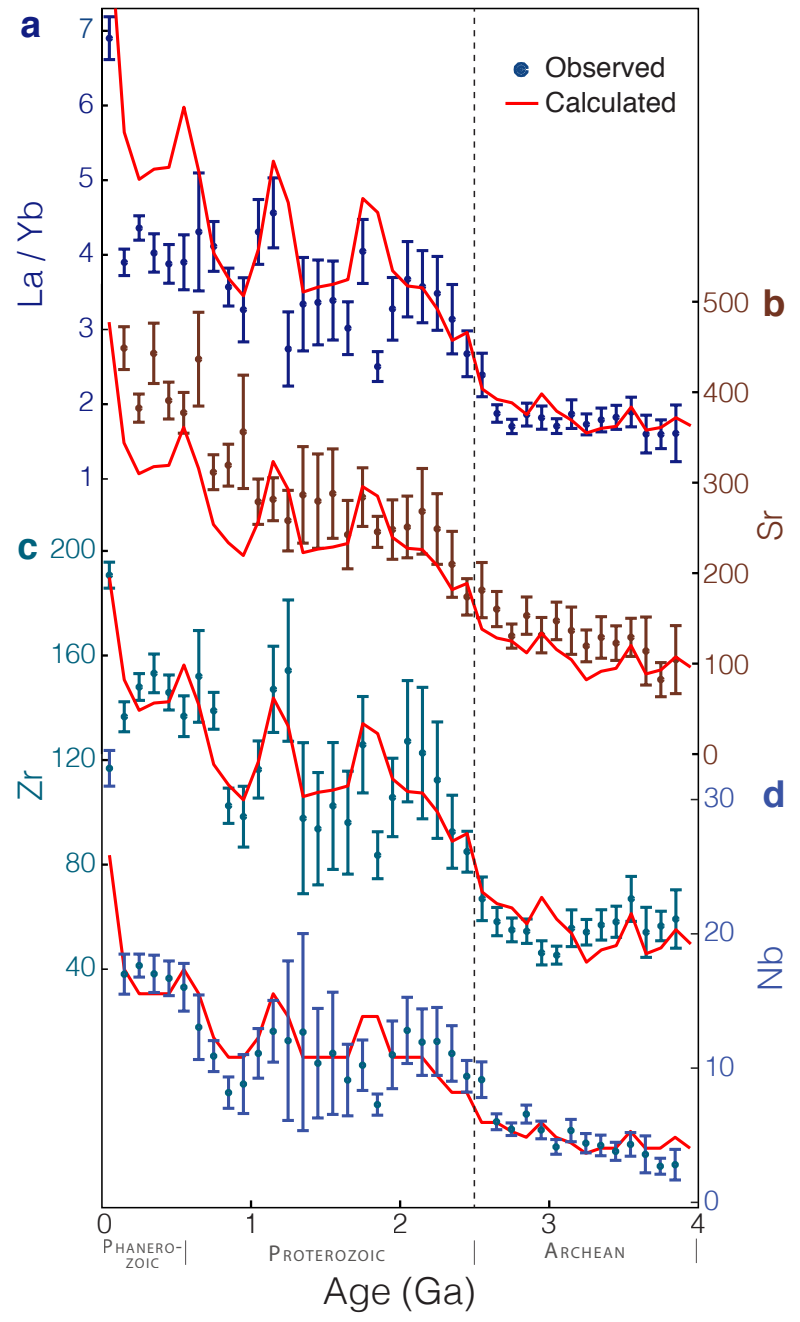

Figure 8: Comparison of observed and calculated basaltic trace element abundances for (a) La/Yb ratio, (b) Sr abundance, (c) $\mathrm{Zr}$ abundance, and (d) $\mathrm{Nb}$ abundance. Calculated values are obtained (as described in the text) using the mantle melting extents from Figure 4, mineral proportions as in Figure 7, GERM partition coefficients, and a constant mantle composition

trace element partitioning calculations (Appendix B). To this end, we first extracted the relative mass of melt and residue present for each temperature step, as well as the proportion of each rock-forming mineral in the corresponding mantle residue. Trace element concentrations in the melt were then calculated using the equilbrium batch melting equation along with mineral/melt partition coefficients derived from the GERM partition coefficient database (GERM, 2013) interpolated as a function of $\mathrm{SiO}_{2}$ as in Keller et al. (2015) by bootstrap resampling. To allow for processes such as slab fluid input and magmatic differentiation which influence the trace element budget more dramatically than the major element budget, the initial primitive mantle trace element composition was inverted by scaling the model to fit the mean of the basaltic record. This trace element budget was subsequently held constant for all time, providing no influence on the model trend over time. Compared to standard primitive mantle trace element estimates (e.g. McDonough and Sun, 1995), this inversion resulted in higher ef- 
fective mantle trace element abundances, particularly of fluid mobile elements - consistent with an enriched slab fluid input.

The results reveal that at pressures typical for mantle wedge flux melting, garnet and clinopyroxene are both exhausted in the residuum at $\sim 30 \%$ melt (Figure $7 \mathrm{a}$ ), resulting in a discontinuous break in slope for both melt productivity (Figure $7 \mathrm{~b}$ ) and peridotite/melt partition coefficients (Figure 7c). The nonlinearity and discontinuous slope of the percent melt-temperature relationship in Figure $7 \mathrm{~b}$ are responsible for reconciling the discontinuous percent melt-time curve in Figure $4 \mathrm{a}$ with the smooth temperature-time curve in Figure 4b. Applying the partition coefficients from Figure $7 \mathrm{c}$ to the percent melt-time trend from Figure 5a accurately reproduces observed trace element trends, as seen in Figure 8, with no fitting or adjustment of partition coefficients. As with the mantle melting estimates of Section 3.2, calculated trace element trends are not substantially altered by substituting continuous fractional polybaric melting in place of isobaric batch melting (Supplementary Figure 10).

\section{Discussion}

\subsection{Constraints on the prevalence of subduction through Earth history}

The initiation of subduction and modern-style plate tectonics would directly precipitate an increase in average basaltic water content due to the addition of wet basaltic magmas produced by flux melting with $\sim 4.0 \% \mathrm{H}_{2} \mathrm{O}$ (e.g. Plank et al., 2013) to the preexisting population of dry rift and plume basalts produced by decompression melting with only $\sim 0.2 \% \mathrm{H}_{2} \mathrm{O}$ (e.g. Sobolev and Chaussidon, 1996), corresponding to a decrease in tholeiitic index from 1.8 at $0.2 \% \mathrm{H}_{2} \mathrm{O}$ towards 0.8 at $4.0 \% \mathrm{H}_{2} \mathrm{O}$ (Zimmer et al., 2010). However, no such trend is observed in our results (Figure 6d). Instead, average tholeiitic index has held roughly constant at $\mathrm{THI} \simeq 0.9$ since the earliest Archean, indicating a consistent predominance of calc-alkaline differentiation (Figure 6d). This conclusion is strongly supported by a wide range of fluid-sensitive trace element signatures including $\mathrm{Nb} / \mathrm{Th}, \mathrm{K} / \mathrm{Hf}$, and $\mathrm{Rb} / \mathrm{Nb}$ (Figure 6a-c,e), all of which show no systematic variation in the relative extent of slab fluid in put since the earliest Archean. Indeed, since arc basalts today display higher degrees of melting than coeval rift and plume basalts (Watson and McKenzie, 1991; Kelley et al., 2010) due to the increased water content of arc basalts, the sudden addition of hydrous arc basalts to the geologic record would arguably result in a rapid increase in average mantle melting extent, which is not observed at any time in the preserved rock record (Figure 4).

Objections to Archean plate tectonics have been raised on a wide variety of grounds, notably among them the absence from the preserved Archean record of certain rock types considered characteristic of plate tectonics (Hamilton, 1998; Stern, 2008). For example, blueschists and ultra-high pressure (UHP) metamorphic terranes, considered to form exclusively at subduction zones, first appear in the early Neoproterozoic, broadly concomitant with an increase in the occurrence of preserved ophiolites (Stern, 2008; Brown, 2007; Harlow et al., 2015). However, a Neoproterozoic start to plate tectonics would conflict with an abundance of geologic evidence thought to reflect modern-style horizontal tectonics well before this time, including the forma- tion of the well-established supercontinent Rodinia (e.g. Hoffman, 1988; Li et al., 2008). Such conflicts may be resolved by incomplete preservation in the geologic record: in light of preservation bias, the first appearances of plate tectonic hallmarks supply only one-sided constraints - providing evidence of plate tectonic processes at a given date, without necessarily ruling out earlier operation. This effect of preservation bias is broadly applicable to a wide range of records. For example, Shirey (Shirey and Richardson, 2011) provide a global record of lithospheric inclusions in diamond, identifying eclogitic inclusions as old as $3.0 \mathrm{Ga}$, but only peridotitic inclusions prior to that time. Due to Os isotopic enrichment, the eclogitic inclusions provide evidence for subduction and underplating of basaltic crust (Richardson et al., 2001). However, the absence of observed eclogitic inclusions older than $3 \mathrm{Ga}$ does not exclude subduction before this date; unlike depleted lithospheric peridotite, eclogite is denser than the underlying asthenosphere and thus subject to delamination - a process which is only expedited by higher mantle temperatures (Jull and Kelemen, 2001) which likely prevailed in the Archean.

Moreover, the existing constraints are highly temporally heterogeneous. Consider, for example, the first known appearance of jadeitites by $520 \mathrm{Ma}$ (Harlow et al., 2015); UHP metamorphic terranes by $\sim 620 \mathrm{Ma}$ (Liou et al., 2014); lawsonite-bearing blueschists by $\sim 750 \mathrm{Ma}$ (Tsujimori and Ernst, 2014); complete ophiolites by $1998 \mathrm{Ma}$ (Scott et al., 1992); seismically-imaged crustal sutures by $2.69 \mathrm{Ga}$ (Calvert et al., 1995); paired metamorphic belts by $\sim 2.7 \mathrm{Ga}$ (Brown, 2006); isotopically evolved, underplated eclogites by $2.89 \mathrm{Ga}$ (Richardson et al., 2001); continental rifting by $3.2 \mathrm{Ga}$ (Van kranendonk and Smithies, 2007); boninites and fragmentary ophiolite-like accreted oceanic terranes by 3.7 Ga (Polat et al., 2002; Komiya et al., 1999; Furnes et al., 2007); and crust/mantle isotopic recycling by at least 3.9 $\mathrm{Ga}$ (Shirey et al., 2008). Compared to geochemical and isotopic signatures that are readily preserved even after extensive metamorphism, many of the earlier entries in this list display poor preservation potential.

Jadeitites, blueschists, and other very high pressure, low temperature metamorphic rocks are thermodynamically fragile far out of thermodynamic equilibrium in any cratonic geotherm - and are difficult to successfully exhume and preserve even in modern arcs (Ernst, 2003); such assemblages may not have formed in ancient subduction zones with higher mantle temperatures and more Mg-rich oceanic crust (Palin and White, 2015). Ophiolites, meanwhile, remain recognizable after more extensive metamorphism and alteration, but are susceptible to erosion due to both their chemical weatherability and their emplacement by obduction atop existing continental crust. At the other extreme, geochemical subduction signatures and isotopic tracers of crustal recycling can be preserved in principle as far back in time as the earliest surviving rocks and minerals. If the pervasive diachroneity of these data is the result of preservation bias, we should then be led to conclude that the oldest preserved constraint is the most accurate.

Meanwhile, the geochemical constraints (Figures 3, 6) are difficult to escape. The effect of water on the extent of calc-alkaline differentiation is well established, and the major elements by which this effect is quantified are not readily biased (e.g. Sisson and Grove, 1993; Zimmer et al., 2010). The effect of slab flu- 
ids to produce relative enrichment of fluid-mobile elements and depletion of non-mobile elements is similarly well established (Perfit et al., 1980; Tatsumi et al., 1986; McCulloch and Gamble, 1991; Pearce and Peate, 1995; Schmidt and Poli, 2014), with no clear mechanism available to mask the absence of such arc signatures from the geologic record in the absence of subduction. If anything, the progressive leaching of fluid-soluble elements such as $\mathrm{Rb}$ from older rocks would only enhance such an effect. Together, we are left to conclude that the global longterm average proportion of flux and dehydration melting has not changed systematically at any time in the preserved rock record, and that subduction of oceanic crust has likely been in operation since at least the earliest Archean.

Nonetheless, our results need not preclude the operation of novel, nonuniformitarian processes in the Archean e.g., widespread intracrustal diapirism (Van kranendonk and Smithies, 2007) - as long as such processes are compatible with the constant proportion of flux and decompression melting preserved in the continental basaltic record. Some of the most intriguing features of Earth's igneous rock record are endemic to the Archean, including granite-greenstone terranes, trondhjemites and komatiites. While our results suggest that basalts are generated by largely the same processes today as they were in the in the Archean, rapid ( $<200 \mathrm{Myr})$ transitions in granitic trace element compositions $2.5 \mathrm{Ga}$ ago (Keller and Schoene, 2012) appear to suggest a change in the process of crustal differentiation, which remains coincident with widespread atmospheric oxidation at the end of the Archean.

\subsection{Implications of ongoing subduction throughout the preserved rock record}

The observed $\mathrm{TiO}_{2}-\mathrm{MgO}$ and $\mathrm{Na}_{2} \mathrm{O}-\mathrm{MgO}$ systematics (Figure $3 e-f)$ tentatively suggest a continual, progressive increase in the average depth of mantle melting over Earth history - opposite the expectation from secular mantle cooling in a mantle decompression melting scenario (Iwamori et al., 1995). In a plate tectonic flux melting regime, however, the depth of flux melting is generally thought to decrease with increasing mantle potential temperature due to dehydration of the slab at lower pressures if all else is held constant (Peacock, 1990; Schmidt and Poli, 2014). One complication to this model arises from the fact that the composition of subducting slabs has not been constant through Earth history. Recently, Palin and White (2015) have suggested that more Mg-rich Archean slabs contain more stable hydrous minerals that can carry more water to greater depths, acting counter to the effect of increased mantle potential temperature. Mantle lithosphere, which may control the depth of last magma equilibration with the convecting mantle, provides another potential complication. Given that preserved continental lithosphere is roughly coeval with its overlying crust (Pearson, 1999), and increases in thickness towards the Archean (Artemieva, 2006), one might expect deeper depths of last magma equilibration in the Archean - also contrary to the observed pressure trends. However, this complication applies in detail only to decompression melting below preexisting continental crust with an extant mantle lithosphere; the depth of last equilibration in modern arc settings appears to be set instead by crustal thickness (Plank and Langmuir, 1988), suggesting that a highly rigid mantle lithosphere is not yet present in arc settings. While there is much room for further research, the trend in melting pressure suggested by Figure 3e-f may well be most consistent with a predominance of flux melting in the continental basaltic record, as is suggested by the consistently calc-alkaline $(\mathrm{THI}<1)$ average observed tholeiitic index in Figure $6 \mathrm{~d}$

Other features of the observed basaltic record, such as the rapid $(<1 \mathrm{Gyr})$ shift in trace element ratios $(\mathrm{La} / \mathrm{Yb}$, etc.), are similarly internally consistent with a plate tectonic setting, given that mineral stability thresholds in an arc mantle wedge setting readily explain the observed trends (Figure 8). While we have not attempted to quantify the extent of the apparent increase in average mantle melting pressure, one notable consequence would be to shift the site of flux melting from the garnet peridotite stability field towards the spinel peridotite stability field in early Earth history - though potentially to little effect given the apparent extent of mantle melting beyond the point of garnet and clinopyroxene exhaustion in the Archean (Figures 4,7).

Even within a plate tectonic regime, the constant average continental basaltic water content and slab fluid input since $\sim 4 \mathrm{Ga}$ is notable, suggesting a roughly constant proportion of arc and non-arc magmatism in the preserved continental record. If accurate, these results demonstrate that a constant ratio of flux to decompression melting is a persistent feature of terrestrial plate tectonics on Ga timescales.

\section{Conclusions}

The integration of large, freely available geochemical datasets with computational statistical methods has allowed for the quantification of systematic changes in average basaltic composition over time (Figures 1-6), including gradual (Figure 1), abrupt (Figure 5), and invariant (Figure 6) trends at the 4-Ga scale. Although it is not possible to demonstrate complete independence of these results from sampling and preservation bias, weighted bootstrap resampling provides a robust method to obtain maximally representative information from the heterogenous rock record. Internal consistency of the resulting trends, along with observed variations contrary to expected weathering and preservation biases, provides some confirmation that the results likely reflect secular variation in underlying drivers of the Earth system. These trends represent a significant advance in our ability to quantify changes in the composition of Earth's crust over time, allowing us to build our understanding of geological rates, states, and processes back through Earth history from the known state of the present.

Due to the lack of any systematic variation in abundance ratio for element pairs with similar igneous partitioning behavior but contrasting mobility during alteration and weathering (Figure 2, $5 a-b)$, we consider that these trends reflect igneous variability attributable to systematic temporal changes in magmatic process driven by mantle thermal state. An igneous origin for observed basaltic major and trace element geochemical trends is consistent with the interpretation of Keller and Schoene (2012) that the smoothly decreasing compatible and increasing incompatible element trends of average basalt over the past $4 \mathrm{Ga}$ (Figure 1) reflect decreasing average extent of mantle melting driven by secular mantle cooling. This interpretation is supported by the distinct observed signature of decreased partial melting relative to increased magma differentiation (Figure 2) 
and the lack of apparent variation in average basaltic magma water content since $4 \mathrm{Ga}$ (Figure 3b-c, 6). Moreover, when properly accounting for the effects of mineral stability thresholds on trace element partitioning and melt productivity, (Figures 7), it is observed that even the most abrupt observed transitions in trace element geochemistry are consistent with smooth, continuous mantle cooling as observed in Figure 8.

Consequently, we propose that the geochemistry of the preserved basaltic crustal record can be most parsimoniously explained by plate tectonic processes modified by secular mantle cooling. In this interpretation, rapid variations in the geochemical record at the end of the Archean are effectively explained by the discontinuous effects of mineral stability thresholds on the petrologic processes of magma generation and differentiation, specifically garnet and clinopyroxene exhaustion during mantle partial melting. In addition to the consistent reproduction of observed trace element geochemistry (Figure 8), support for this model comes from its reconciliation of a discontinuous (at the 2-standard-error level) percent melt trend with a smooth and continuous mantle melting temperature trend as observed in Figure 4.

This model is reinforced by the invariance of geochemical slab fluid input signatures through geologic time (Figure 6a-c,d) which indicate a roughly constant proportion of crust produced in subduction zones over the entirety of the preserved rock record. Together, this evidence favors a horizontal, largely uniformitarian model of Archean tectonics. Given the profound geologic consequences of a planetary transition from a stagnantlid or vertical tectonic regime to horizontal plate tectonics, the invariance of slab fluid and flux melting signatures (Figure 6) and the consistency of the basaltic record with simple secular mantle cooling (Figure 8) both suggest that subduction and associated horizontal tectonics had begun on Earth by at least 3.8 $\mathrm{Ga}$ and have operated consistently since.

\section{Appendix A: The WeIGHTED Bootstrap ReSAMPLING METHOD}

To obtain an optimally even spatiotemporal sample weighting, each sample is assigned a weight inversely proportional to its proximity to other samples in space and time. Subsequently, the data are resampled (with replacement) in accordance with this weight such that data points from sparsely represented regions of the crust are resampled more frequently, while those from densely sampled regions are selected less frequently. Meanwhile, analytical uncertainty is accurately represented at each resampling step by the addition of Gaussian noise with appropriate variance for each variable in the dataset. The result is a continuous temporal record of the composition of preserved, exposed crust, represented as mean and two-standard-error uncertainty of the mean for $100 \mathrm{Ma}$ time intervals over the last $4 \mathrm{Ga}$ (e.g., Supplementary Figure 1). Spatial and temporal prior and posterior sample distributions for the mafic sample subset examined in this paper are shown in Supplementary Figure 2.

This bootstrap resampling methodology was introduced and discussed by Keller and Schoene (2012), but several points may bear further emphasis. In particular, the proximity of any sample $i$ to all other samples in the dataset is calculated as a proximity sum of the form:

$$
k_{i}=\sum_{j=1}^{n}\left(\frac{1}{\left(\left(z_{i}-z_{j}\right) / a\right)^{2}+1}+\frac{1}{\left(\left(t_{i}-t_{j}\right) / b\right)^{2}+1}\right)
$$

where $\mathrm{n}$ is the number of samples in the dataset, $\mathrm{z}$ is spatial location, $\mathrm{t}$ is sample age, and $a$ and $b$ are constants where $a=1.8$ arc degrees and $b=38$ Myr. This equation and the associated constants are derived as follows.

We wish to obtain a more uniform sample distribution in space and time by assigning a greater weight (or resampling probability) to any samples that are far away from other samples in space and time. However calculating sample weight on the basis a naive distance sum will obviously not suffice, as this will be dominated only by far-field samples. A sum of inverse distances may be more appropriate, but this will introduce a singularity in the case of samples with identical positions. Instead, we desire to sum over a variable that should equal 1 for two samples with identical position, and 0 for two samples infinitely far apart. Consequently, we define proximity for some position variable $\mathrm{x}$ as:

$$
\frac{1}{(\Delta x / s)^{p}+1}
$$

where $\mathrm{s}$ and $\mathrm{p}$ are constants. Any positive real values for $\mathrm{s}$ and $\mathrm{p}$ will satisfy our requirement that proximity is one when $\Delta x=0$ and approaches zero as $\Delta x$ approaches infinity. From inspection, it is clear that greater values of $\mathrm{p}$ diminish the proximity value for sample pairs with $\Delta x>s$ and increase the proximity value for sample pairs with $\Delta x<s$

When combining proximities for two variables that do not share a scale (e.g., space and time), we have a choice of scale constant for each variable. For geologic time and distance on the surface of the Earth, we have a clear maximum scale for each: 180 arc degrees for space, and $\sim 3800$ Myr for the preserved continental rock record; this helps us set the desired proportionality between $a$ and $b$. We must also consider the relative importance of near-field versus far-field samples. In considering a single geologic sample, the proximity of that sample to any number of samples on the other side of the Earth should not greatly influence the resampling probability. Instead, we wish to emphasize spatial and temporal differences on the scale of the fundamental unit of the igneous rock record: a single pluton or a single magmatic episode. As higher values of $p$ diminish the proximity value of far-field samples and increase that of near-field samples (relative to scales $a$ and $b$ ), we would like to set $p>1$ along with $a$ and $b$ near the scale of a pluton or magmatic event. Within these constraints, variations in the exact value of $p$ have relatively little impact on the resultant temporal trends (Supplementary Figure 3)

A pluton or batholith may have a spatial scale up to tens or hundreds of $\mathrm{km}$ and a lifetime up to ones or tens of million years. Setting $a=1.8$ arc degrees (200 km) and $b=3.8 \mathrm{Myr}$ satisfies these constraints while maintaining the desired proportionality between spatial scale and temporal scale. However, different weights may be chosen if one wishes to study a process with a different fundamental scale.

Having now a full expression for the proximity norm of any two samples, we may calculate the proximity sum $k_{i}$ for each sample $i$ relative to all other samples $j=1$ to $n$. However, as defined, $k_{i}$ will vary as a function of the total number of samples in the dataset, as well as the choice of constants $a, b$, and $p$. We thus require a normalization constant $c$, which may be adjusted to set the mean or median resampling probability (typically $\sim 0.2$ : lower mean resampling probability would allow for greater improvements in sample evenness, but at the cost of sample richness). We then may calculate sample weight:

$$
W_{i}=\frac{1}{k_{i} / c}
$$

where an infinite weight corresponds to a $100 \%$ probability of resampling, or equivalently:

$$
P_{i}=\frac{1}{k_{i} / c+1}
$$

the resampling probability. 
Given the the resampling probability for each sample, the full dataset may be resampled (with replacement) as many times as desired, binned by the independent variable of choice (typically age, in this study), and means and two-standard-error uncertainties calculated for each age bin Convergence may occur within as few as $\sim 50-100$ iterations, but even the conservative default of $\sim 10,000$ iterations is not computationally prohibitive. Notably, where the dependent variable is a ratio of two elemental analyses, as in (Keller and Schoene, 2012) we represent each element pair as a fraction $a /(a+b)$ prior to binning (for each analysis with both elements $a$ and $b$ defined), and subsequently return the binned results to $a / b$ ratio form; this fractional average avoids the numerical instability inherent in ratios where the denominator may approach zero. Finally, although geological age uncertainties may be correlated, for e.g., samples derived from the same pluton or outcrop, the binned results are conveniently found to be relatively insensitive to the presence or absence of even quite extreme correlations in independent variable uncertainty (4).

While such weighted resampling reduces sampling bias, it cannot eliminate it completely (e.g., rocks that were never sampled cannot be included in the dataset). Similarly, rocks that have been lost from the crustal record or are otherwise not presently exposed on Earth's surface are necessarily absent from our record. The resulting preservation and exposure bias cannot be corrected without quantitative knowledge of the relationship between preservation / exposure potential and composition. The displayed two-standard-error uncertainties throughout this paper show only how well we know the average composition for basaltic rocks of a given age assuming a random, unbiased sampling of the crust, and thus must be treated as minimum uncertainties. Consequently, sampling, preservation, and exposure bias should be considered when interpreting temporal geochemical trends.

These limitations notwithstanding, the quantification of average compositions for preserved, surficially exposed continental crust through time provides an invaluable window into the deeper workings of the Earth system due to the ability of averages to isolate meaningful signals of secular variation from the heterogeneous rock record. Reducing a geochemical variable to a single global average scalar necessarily discards information. However, this reduction in complexity mitigates the effect of many confounding processes (e.g. local variability in structural/tectonic setting, mantle heterogeneity, partitioning within the sample set, etc.) such that the resulting average value is a more representative estimator of underlying secular variation. This follows directly from the significance of the arithmetic mean as an analogue for physical homogenization, and can be considered to reflect the inverse relationship between sample size and signal/noise ratio.

This above effect is crucial for our purposes, since temporal variations in crustal composition are typically dwarfed by the instantaneous geochemical variability of the igneous rock record at any given time. Even though our resampled averages are likely not perfectly representative, they are the most representative data available at present, and are observed to display properties consistent with first-principles expectations, e.g, for secular temporal variation in mantle potential temperature. Observed variations follow clear systematics as expected on the basis of elemental compatibility during mantle melting (Supplementary Figure 5) and are broadly robust for a range of $\mathrm{SiO}_{2}$ and $\mathrm{MgO}$ windows which may be considered to encompass the majority of mantle-derived magmas (Supplementary Figure 6).

When interpreting the obtained results, it is worth bearing in mind that neither mid-ocean ridge basalts nor mantle plume basalts are common in the continental record. Since we include only samples geographically originating from present-day continental crust, non-continental basalts such as mid-ocean ridge basalts and ocean island basalts are excluded from our record except where they have been incorporated into the continental crust by natural geologic processes such as obduction. This exclusion is fully intentional, given that we are attempting to understand in particular the formation of the continental crust. Conse- quently, no subsequent geochemical interpretations should be considered representative of non-continental basalts such as MORB or OIB, nor the source mantle thereof.

The results demonstrate that weighted bootstrap resampling of a sufficiently large global dataset reveals a consistent set of clear temporal trends in average basaltic composition over Earth history. These trends are resolvable only thanks to the statistical properties of large sample sets, demonstrated in the general case by the law of large numbers. Although individual basalt compositions may vary widely from the true population mean due to geological (and to a lesser degree analytical) sources of variance, the effect of this variance on the mean of the observed sample set diminishes in proportion to the number of independent data in the set; equivalently, the standard error of the observed mean decreases as the square root of the number of independent data. Consequently, while it is impractical to exclude all low-quality data from a large dataset, even highly uncertain data provide new information about the population mean as long as individual sample compositions are independent and accurate to within their stated uncertainty.

Since both geological and analytical uncertainty are the result of successive convolutions of many independent sources of error, the resulting distribution of the uncertainty will (following the Central Limit Theorem) will approach a Gaussian distribution as the number of sources of error increases. Moreover, even drawing from a highly nonGaussian distribution of geochemical data, the probability distribution of the mean will also approach a Gaussian distribution in accordance with the central limit theorem, such that variance and standard deviation are appropriate parameters with which to characterize the variability of the mean (Keller and Schoene, 2012). The result is a statistically robust record of secular geochemical evolution on which to build interpretations of geologic process.

Additional discussion of the weighted bootstrap resampling method and the standard error of the mean can be found in the full methods of Keller and Schoene (2012). In particular, we note that any rate of change derived from our Monte Carlo method is a minimum: geochronological uncertainty acts to smooth any rapid discontinuites into a continual transition. This effect applies even in the case of a gap in the underlying data, as discussed by Keller and Schoene (2012). Nonetheless, we note that our coarse binning resolution of $100 \mathrm{Myr}$ implies that we cannot conclusively distinguish an instantaneous discontinuity from a protracted transition occurring over as much as 200 $\operatorname{Myr}$ (i.e., due to a Nyquist frequency of 1/200 $\mathrm{Myr}^{-1}$ ).

\section{APPENDIX B: ALPHAMELTS CALCULATIONS AND TRACE ELEMENT MODELLING}

To obtain thermodynamic insight into the geochemistry and equilibrium mineralogy of mantle partial melting, we conduct a wide range of pMELTS simulations (Ghiorso et al., 2002; Asimow et al., 2004) via the alphaMELTS command-line batch interface (Smith and Asimow, 2005). Such pMELTS simulations are used to (1) asses the sensitivity of major element melting differentiation trends to changes in melting extent and melting pressure, (2) invert for average mantle melting extent from the observed whole-rock major element record, and (3) estimate modal mineralogy of the mantle residue during partial melting to inform trace element partitioning calculations.

\section{Deconvolving fractional crystallization, partial melting, and melting pressure}

In order to differentiate between fractional crystallization and mantle partial melting in the continental magmatic record, we use a range of bivariate differentiation plots where the opposing effects of mantle melting extent and fractional crystallization extent are oblique rather than subparallel in cross-plot space (Figure 3). To inform the 
schematic effect direction arrows shown in Figure 3, pMELTS simulations are conducted and plotted for each diagram over a range of pressures and melting extents, using a Matlab script to automate interaction with the alphaMELTS command-line interface, as illustrated in Supplementary Figure 7. Since each observed differentiation line shares a common global mantle potential temperature (and global average mantle melting extent), fractional crystallization dominates the differentiation trend within a single time interval, while changes over time perpendicular to this trend are driven by either changes in mantle melting extent or (in some cases) melting pressure.

Specifically, the effects of melting pressure and melting extent were quantified by pMELTS simulations for equilibrium batch melting of primitive (McDonough and Sun, 1995) mantle, with 0.1 to 1 wt. \% $\mathrm{H}_{2} \mathrm{O}$ and pressures ranging from 1 to $3 \mathrm{GPa}$ in $250 \mathrm{MPa}$ increments and with a fixed oxygen fugacity set by the fayalite-magnetite-quartz buffer. The results of changing melting extent or water content are typically straightforward, while changing melting pressure may have more indirect implications. For instance, increasing pressure both increases solidus temperature and increases melt $\mathrm{MgO}$ for a given melting extent, resulting in higher concentrations of mantle-incompatible elements such as $\mathrm{Na}$ or $\mathrm{Ti}$ at a given $\mathrm{MgO}$ content (or equivalently, higher $\mathrm{MgO}$ at a given $\mathrm{Na}_{2} \mathrm{O}$ ).

These results are consistent a range with experimental observations The observation of increasing melt $\mathrm{MgO}$ as a function of increasing pressure at constant melt fraction is well known (e.g., Klein and Langmuir, 1987). Since we do not attempt to isolate or reconstruct primitive unfractionated magma compositions, we cannot observe this effect directly, but instead observe it indirectly through incompatible element systematics at constant MgO. For instance, Herzberg and Zhang (1996) illustrate that, at constant mantle melting extent, increasing mantle melting pressure decreases $\mathrm{Na}_{2} \mathrm{O}$ by nearly a factor of three (e.g. from $\sim 5.7$ to 2 wt. \%), but increases melt $\mathrm{MgO}$ by more than a factor of five (from $\sim 5$ to 27 wt. \%). However, equilibrium lines for variation in $\mathrm{Na}_{2} \mathrm{O}$ with variable extent of melting or differentiation at constant pressure are much steeper in $\mathrm{Na}_{2} \mathrm{O}-\mathrm{MgO}$ space, such that at a $2 \mathrm{GPa}$ magma with 10 wt. $\% \mathrm{MgO}$ has nearly twice the $\mathrm{Na}_{2} \mathrm{O}$ content at equilibrium of a $1 \mathrm{GPa}$ magma at $10 \mathrm{wt}$. \% MgO. Analogous effects should apply for any mantle-incompatible element that increases steeply with decreasing $\mathrm{MgO}$.

Increased Na partitioning into clinopyroxene with increasing pressure introduces an additional complicating factor when considering the above pressure systematics; however, even at high pressure ( $\sim 6 \mathrm{GPa})$, $\mathrm{D}_{\mathrm{Na}}^{C p x / \text { Melt }}$ does not exceed one, and thus does not strongly sequester $\mathrm{Na}$ (Blundy et al., 1995). Indeed, at intermediate pressures appropriate to arc mantle melting (2-3 $\mathrm{GPa}) \mathrm{Na}$ remains generally incompatible in clinopyroxene, $\left(\mathrm{D}_{\mathrm{Na}}^{\mathrm{Cpx} / \text { Melt }} \approx 0.2-0.3\right)$. Instead, $\mathrm{Na}_{2} \mathrm{O}$ and $\mathrm{TiO}_{2}$ show equivalent systematics in Figure 3, consistent with the hypothesis that both $\mathrm{Na}$ and $\mathrm{Ti}$ are both acting only as passive incompatible markers recording the underlying increase in primary magma $\mathrm{MgO}$ with pressure.

\section{Estimating mantle melting extent}

Quantitative estimates of mantle melting extent are produced by inversion of the resampled basaltic whole rock dataset as discussed in Section 2.2.4. In this procedure, each basaltic major element whole rock analysis in each of the $(10,000)$ weighted bootstrap sample sets is assigned a mantle melting extent by least-squares comparison to model mantle melt compositions for a range of melting extents from 0 to $100 \%$ melt at temperatures between the solidus and the liquidus. After assigning a best-fit mantle melting extent and temperature for each (resampled) analysis, these variables are reduced in the same manner as any of the other resampled geochemical variables, to yield a mean and standard error for $100 \mathrm{Myr}$ age bins between 0 and $3900 \mathrm{Myr}$ The required model compositions are produced by pMELTS-mode al-
phaMELTS simulations for primitive mantle melting under a range of model melting conditions and melting modes including isobaric batch melting and continuous fractional polybaric melting.

Figure 4 illustrates the results in the case of isobaric batch (equilibrium) melting of McDonough and Sun (1995) primitive mantle ("pyrolite") with oxygen fugacity fixed by the fayalite-magnetite-quartz buffer and 0.15 wt.\% initial $\mathrm{H}_{2} \mathrm{O}$ at 2.2, 2.7, and $3.2 \mathrm{GPa}$, calculated between the liquidus and the solidus in $10^{\circ} \mathrm{C}$ increments. Since mantle melting extent is estimated for each individual (resampled) whole-rock analysis for each set of pMELTS results, each (resampled) whole-rock analysis is individually assigned a estimated melting extent and estimated melting temperature. While estimated melting extents and subsequent averages are expected to be relatively insensitive to variations in the melting model, the corresponding estimated melting temperatures are obviously highly model dependent. Consequently, to asses the robustness of these results to data quality and model assumptions, a wide range of sensitivity tests have been conducted.

While the results appear to fall within an a-priori reasonable range (as discussed in the text), their accuracy is in part dependent on the degree of correlation among the error terms introduced for each separate major-element record by each potential confounding igneous process (fractional crystallization, phenocryst accumulation, assimilation, slab fluid input, etc.). In the simplest case of fully uncorrelated errors for $\mathrm{N}$ major elements, error in the end result (e.g., mantle melting extent) would decrease by a factor of $\sqrt{N}$. Fully correlated errors, which would arise if the effects of confounding processes such as fractional crystallization were fully parallel to the mantle melting path in $\mathrm{N}$-dimensional major element space, would allow for no reduction in the confounding bias. In reality, each of the above confounding processes acts neither parallel nor perpendicular to the mantle melting path, with precise effects varying as a function of numerous geological variables for each sample. Consequently, the resulting mantle potential temperature and melting extent estimates should not be taken as absolute. Potential igneous biases are schematically illustrated in Figure 4, and should be kept in mind throughout.

Firstly, to test sensitivity of the results to the presence of high-MgO lithologies such as komatiites or cumulates, the mantle melting extent calculations are repeated excluding all analyses with more than 18 wt. \% MgO, shown in Supplementary Figure 8. Due to their exceptional petrology and general rarity outside the Archean, komatiites are sometimes considered separately from other mantle-derived magmas. While excluding komatiites from the mafic magma set substantially decreases average Archean $\mathrm{MgO}$ abundances, it has little impact on most other major elements trends such as $\mathrm{CaO}, \mathrm{Al}_{2} \mathrm{O}_{3}, \mathrm{TiO}_{2}, \mathrm{Na}_{2} \mathrm{O}$ or $\mathrm{K}_{2} \mathrm{O}$, and thus only modestly decreases estimated average potential temperatures and melting extents. While excluding komatiites would likely be prudent if attempting to estimate, e.g., Archean oceanic basalt compositions or mid-ocean ridge melting conditions, Archean komatiites nonetheless represent real mantle-derived magmas preserved in the continental record, and thus should not be excluded from our continental sample set. However, as shown in Supplementary Figure 8, even if we were to exclude komatiites, the impact on estimated mantle potential temperature and melting extent would be unexceptional.

Similarly, reasonable variations in the compositional (least-squares) comparison procedure also have little impact on on the results, as illustrated in Supplementary Figure 9. While in many cases samples with lower residuals may be considered more reliable, this is not necessarily the case here, given the substantial nonuniqueness of model melting curves introduced by uncertainty regarding the $\mathrm{P}, \mathrm{T}, \mathrm{H}_{2} \mathrm{O}$, etc. conditions of mantle melting (c.f. Supplementary Figure 7). Given the cost to sample richness and evenness of excluding half the potential sample population, it is not clear that excluding high-residual samples should be expected to yield more accurate results. In either case, the results 
are not dramatically altered when high-residual samples are excluded (Supplementary Figure 9).

More complicated considerations involve the choice of mantle melting style. While isobaric equilibrium melting provides a simple, computationally stable, and reversible model, real mantle melting is rarely isobaric, and only asymptotically approaches equilibrium. Since equilibrium melting is path-independent, polybaric equilibrium melting would be equivalent to isobaric melting at the pressure of last equilibration. In the case of fractional melting, however, polybaric and isobaric melting may yield distinct results. As an alternative endmember model to (isobaric) equilibrium melting then, we may consider continuous polybaric fractional melting, where new increments of melt are removed and completely isolated from the solid once they exceed an abundance threshold of, e.g. $0.001 \mathrm{wt}$. \%. Such an alternative model is explored in Supplementary Figure 10.

Given the arc genesis expected for many of the basalts preserved in the continental record, the polybaric fractional melting model used in Supplementary Figure 10 follows a P-T path of the form that might be experienced by a packet of upwelling mantle in a subduction zone mantle wedge, beginning at the hydrous solidus just above at slab at $3.3 \mathrm{GPa}$ and increasing in temperature with decreasing pressure until 2 GPa (c.f. Grove et al. (2012)). Continuous melting fractional melting is enabled using the ALPHAMELTS_CONTINUOUS_MELTING option, with the ALPHAMELTS_MASSIN environment variable set to $0.001 \mathrm{~g}$ for a $100 \mathrm{~g}$ system to establish a $0.001 \mathrm{wt}$. \% melt extraction threshold. While the vertical structure of the arc mantle melting region (and thus melting pressure) is constrained by the geometry of the mantle wedge, variations in global mantle potential temperature will be reflected by variations in potential temperature at the core of the mantle wedge. Consequently, the melting simulation is repeated for 82 distinct $\mathrm{P}$-T paths with maximum temperatures ranging from 1265 ${ }^{\circ} \mathrm{C}$ to $1675^{\circ} \mathrm{C}$ in $5^{\circ} \mathrm{C}$ increments.

As seen in Supplementary Figure 10a, this radical change in melting model has little impact on the global average mantle melting extent estimated over the past 4 Gyr. However, the estimated mantle potential temperature inverted using for a continuous polybaric fractional melting model markedly exceed those calculated for the isobaric equilibrium case (Supplementary Figure 10b). This latter deviation is attributed to tendency of fractional melting to relegate all water to the isolated melt after the first few fractional melting steps, leaving the residue dry and thus driving up the liquidus temperature, as seen in Supplementary Figure 10c. Such an effect is not considered realistic, deriving from the arbitrarily efficient melt segregation of the continuous melting model. However, a more accurate full reaction-infiltration model is not yet feasible in alphaMELTS, and would more closely approach the equilibrium melting model.

Finally, to more empirically validate the mantle melting model, we have conduct a range of inversions for modern mantle melts including MORB, OIB, and arc, and continental rift basalts using both isobaric equilibrium melting and polybaric fractional melting models. As seen in Supplementary Figure 11, variations in estimated melting extent between different melting models are easily resolvable, but are small in absolute terms relative to the variations observed over the past $4 \mathrm{Gyr}$ ( 3 wt. \% vs $\sim 30$ wt. $\%$ ). Model variation in absolute melting temperature is much more dramatic, given that mantle melting temperature is directly influenced by mantle water content and melting pressure. In mantle potential temperature terms, continuous fractional melting behaves almost as anhydrous melting at similar pressures, since in a strict fractional melting model any initial water is rapidly extracted in the earliest melting steps, and thus is unable to depress melting temperature at any but the very lowest melting extents.

The results of Supplementary Figure 11 highlight the disconnect between mantle melting extent and mantle melting temperature that is introduced by variable $\mathrm{P}$ and $\mathrm{H}_{2} \mathrm{O}$ conditions of mantle melting. For in- stance, while modern plume basalts are generated at higher mantle potential temperatures than modern MOR basalts, the shallowest extent of mantle decompression is limited by impingement on the rigid mantle lithosphere in the case of OIBs, whereas decompression and melting may extend to the surface in modern MORBs. Consequently, the difference in mantle potential temperature between OIB and MORB source mantle does not translate to a corresponding difference in melting extent. Arbitrarily inverting MORB and OIB compositions at the same final equilibration pressures yields unrealistically similar mantle potential temperatures for both lithologies; the true mantle potential difference between MORB and OIB is only evident when each is inverted under geodynamically accurate $\mathrm{P}$ and $\mathrm{H}_{2} \mathrm{O}$ conditions (denoted with asterisks in Supplementary Figure 11b).

Unsurprisingly, MORBs yield reasonable temperatures when inverted assuming shallow and dry final equilibration conditions, OIBs when assuming deep and dry final equilibration, and arcs when assuming deep and hydrous final mantle equilibration (Supplementary Figure $11 b)$. In the case of arcs, melting is enhanced by the input of slab fluids, but hampered by the chilled temperatures of the mantle wedge and the limited extent of decompression due to thick overlying arc crust and/or lithosphere. Together, these observations suggest that while our absolute mantle potential temperature estimates are unavoidably model-dependent, relative temporal trends in temperature are more robust to model variation than are absolute values. As a corollary, we may note that the absolute temperature estimates of Figure 4 which assume generally deep, consistently hydrous mantle/melt equilibration will be most appropriate if our determination of predominant arc origin and consistent proportion of flux melting (c.f. Section 4.1) is correct.

\section{Trace element modelling}

To better understand the observed continental basaltic trace element record, we compare observed trace element trends over the past $4 \mathrm{Gyr}$ to expected trace element trends calculated on the basis of secular mantle cooling. In this model, expected trace element compositions are calculated using GERM mineral/melt trace element partition coefficients along with modal mineral abundances for the mantle residue calculated using pMELTS for the case of equilibrium melting of primitive mantle as above. This melting extent - trace element abundance relationship may then be used to map from mantle melting extent (as determined in Figure 4) to average basaltic trace element evolution over the past 4 Gyr (as in Figure 8).

As in previous simulations to determine average mantle melting extent, modal mineralogy of the mantle residue was determined by pMELTSmode alphaMELTS simulations of isobaric batch melting at $2.7 \mathrm{GPa}$ with a fayalite-magnetite-quartz oxygen fugacity buffer, calculated for $10{ }^{\circ} \mathrm{C}$ increments between the liquidus and the solidus. Residual mineralogy was correlated by temperature for each step, and normalized to yield modal mineralogy for the purposes of bulk solid/liquid partition coefficient calculation.

Since mineral/melt partition coefficients of most elements increase with increasing melt polymerization, GERM partition coefficient data were fit by bootstrap resampling and binned averaging (in log-space) as a function of melt $\mathrm{SiO}_{2}$, as in Keller et al. (2015). Subsequently, appropriate partition coefficients were applied for each mineral in the mantle residue for each melting step in accordance with the appropriate melt $\mathrm{SiO}_{2}$, a bulk solid/liquid partition coefficient calculated, and equilibrium partitioning applied via the partitioning equation

$$
C_{i}^{l}=\frac{C_{i}^{0}}{D^{s / l}(1-F)+F}
$$

where $C_{i}^{l}$ is the concentration of element $i$ in the liquid at for at melt extent $F$ given initial concentration $C_{i}^{0}$ solid/liquid partition coefficient $D^{s / l}$. 
While mantle major element composition may be satisfactorily approximated as primitive mantle during mantle partial melting, the same is not true for trace elements in a subduction zone setting, where trace element budgets are substantially modified by the input of slab fluids. Consequently, the initial trace element budget is inverted by scaling the model mantle trace element curve against the observed trend. However, since this inverted mantle trace element budget is constant for all time, the model is only expected to produce a temporal trend in agreement with the observed trend if (1) the mantle mineralogy and trace element partitioning model accurately reproduces the trace element evolution of the mantle during mantle partial melting, and (2) the melting extents inverted from the major element record alone in Figure 4 record a similar mantle melting history to the trace element record alone. The close agreement of model and observed trace element temporal trends (Figure 8) suggests that both conditions are met.

\section{Author Contributions}

C.B.K. conducted the computations and prepared the manuscript. Both authors contributed to the interpretation of the results.

\section{ACKNOWLEDGEMENTS}

C.B.K. was supported by the Department of Energy Computational Science Graduate Fellowship Program of the Office of Science and National Nuclear Security Administration in the Department of Energy under contract DE-FG02-97ER25308. Reviews by Kent Condie and an anonymous referee substantially improved the manuscript.

\section{Data Availability}

The full dataset and all computational source code is available under an MIT open-source license at https://github.com/ brenhinkeller/StatisticalGeochemistry.

\section{REFERENCES}

Artemieva, I.M., 2006, Global 1EE 1 thermal model TC1 for the continental lithosphere: implications for lithosphere secular evolution: Tectonophysics, v. 416, p. 245-277.

Asimow, P.D., Dixon, J.E., and Langmuir, C.H., 2004, A hydrous melting and fractionation model for midocean ridge basalts: Application to the MidAtlantic Ridge near the Azores: Geochemistry Geophysics Geosystems, v. 5.

Atherton, M. and Petford, N., 1993, Generation of sodium-rich magmas from newly underplated basaltic crust: Nature, v. 362, p. 144-146.

Bédard, J.H., 2006, A catalytic delamination-driven model for coupled genesis of Archaean crust and sub-continental lithospheric mantle: Geochimica et Cosmochimica Acta, v. 70, p. 1188-1214.

Bernstein, S., Kelemen, P.B., and Hanghøj, K., 2007, Consistent olivine $\mathrm{Mg \#}$ in cratonic mantle reflects Archean mantle melting to the exhaustion of orthopyroxene: Geology, v. 35, p. 456-462.

Blundy, J.D., Falloon, T.J., Wood, B.J., and Dalton, J.A., 1995, Sodium partitioning between clinopyroxene and silicate melts: Journal of Geophysical Research: Solid Earth, v. 100 , p. 15501-15515.
Botcharnikov, R.E., Almeev, R.R., Koepke, J., and Holtz, F., 2008, Phase relations and liquid lines of descent in hydrous ferrobasalt-implications for the Skaergaard intrusion and Columbia River flood basalts: Journal of Petrology, v. 49, p. 1687-1727.

Brown, M., 2006, Duality of thermal regimes is the distinctive characteristic of plate tectonics since the Neoarchean: Geology, v. 34, p. 961.

Brown, M., 2007, Metamorphic Conditions in Orogenic Belts: A Record of Secular Change: International Geology Review, v. 49, p. 193-234.

Calvert, A.J., Sawyer, E.W., Davis, W.J., and Ludden, J.N., 1995, Archaean subduction inferred from seismic images of a mantle suture in the Superior Province: Nature, v. 375, p. 670-674.

Condie, K.C., Aster, R.C., and van Hunen, J., 2016, A great thermal divergence in the mantle beginning $2.5 \mathrm{Ga}$ : Geochemical constraints from greenstone basalts and komatiites: Geoscience Frontiers.

Condie, K.C. and Kröner, A., 2008, When did plate tectonics begin? Evidence from the geologic record: In K.C. Condie and V. Pease (eds.), Geological Society of America Special Paper 440: When Did Plate Tectonics Begin on Planet Earth?, p. 281-294, Geological Society of America.

Condie, K.C. and O’Neill, C., 2010, The Archean-Proterozoic boundary: 500 my of tectonic transition in Earth history: American Journal of Science, v. 310, p. 775-790.

Davies, G.F., 2009, Effect of plate bending on the Urey ratio and the thermal evolution of the mantle: Earth and Planetary Science Letters, v. 287, p. 513-518.

de Wit, M.J., 1998, On Archean granites, greenstones, cratons and tectonics: does the evidence demand a verdict?: Precambrian Research, v. 91, p. 181-226.

Ernst, W.G., 2003, High-pressure and ultrahigh-pressure metamorphic belts - Subduction, recrystallization, exhumation, and significance for ophiolite study: In Y. Dilek (ed.), Ophiolite Concept and the Evolution of Geological Thought: GSA Special Paper 373, Geological Society of America.

Furnes, H., de Wit, M.J., Staudigel, H., Rosing, M.T., and Muehlenbachs, K., 2007, A Vestige of Earth's Oldest Ophiolite: Science, v. 315, p. 1704-1707.

GERM, 2013, Geochemical Earth Reference Model Partition Coefficient Database: .

Ghiorso, M.S., Hirschmann, M.M., Reiners, P.W., and Kress, III, V.C., 2002, The pMELTS: A revision of MELTS for improved calculation of phase relations and major element partitioning related to partial melting of the mantle to $3 \mathrm{GPa}$ : Geochemistry Geophysics Geosystems, v. 3, p. 1-36.

Green, D.H., 1975, Genesis of Archean Peridotitic Magmas and Constraints on Archean Geothermal Gradients and Tectonics: Geology, v. 3, p. 15.

Grove, T.L., Chatterjee, N., Parman, S.W., and Medard, E., 2006, The influence of $\mathrm{H} 2 \mathrm{O}$ on mantle wedge melting: Earth and Planetary Science Letters, v. 249, p. 74-89.

Grove, T.L. and Parman, S., 2004, Thermal evolution of the Earth as recorded by komatiites: Earth and Planetary Science Letters, v. 219, p. 173-187. 
Grove, T.L., Till, C.B., and Krawczynski, M.J., 2012, The role of $\mathrm{H} 2 \mathrm{O}$ in subduction zone magmatism: Annual Review of Earth and Planetary Sciences, v. 40, p. 413-439.

Hamilton, W.B., 1998, Archean magmatism and deformation were not products of plate tectonics: Precambrian Research, v. 91, p. $143-179$.

Hargraves, R.B., 1976, Precambrian Geologic History: Science, v. 193, p. 363-371.

Harlow, G.E., Tsujimori, T., and Sorensen, S.S., 2015, Jadeitites and Plate Tectonics: Annual Review of Earth and Planetary Sciences, v. 43, p. 105-138.

Harrison, T.M., 2009, The Hadean Crust: Evidence from $>4$ Ga Zircons: Annual Review of Earth and Planetary Sciences, v. 37, p. 479-505.

Herzberg, C., Condie, K.C., and Korenaga, J., 2010, Thermal history of the Earth and its petrological expression: Earth and Planetary Science Letters, v. 292, p. 79-88.

Herzberg, C. and Zhang, J., 1996, Melting experiments on anhydrous peridotite KLB-1: Compositions of magmas in the upper mantle and transition zone: Journal of Geophysical Research, v. 101, p. 8271-8295.

Hirschmann, M.M., Ghiorso, M.S., Wasylenki, L.E., Asimow, P.D., and Stolper, E.M., 1998, Calculation of Peridotite Partial Melting from Thermodynamic Models of Minerals and Melts. I. Review of Methods and Comparison with Experiments: Journal of Petrology, v. 39, p. 1091-1115.

Hoffman, P.F., 1988, United Plates of America, The Birth of a Craton: Early Proterozoic Assembly and Growth of Laurentia: Annual Review of Earth and Planetary Sciences, v. 16, p. 543-603.

Hofmann, A.W., 1997, Mantle geochemistry: the message from oceanic volcanism: Nature, v. 385, p. 219-229.

Iwamori, H., McKenzie, D., and Takahashi, E., 1995, Melt generation by isentropic mantle upwelling: Earth and Planetary Science Letters.

Jull, M. and Kelemen, P.B., 2001, On the conditions for lower crustal convective instability: Journal of Geophysical Research, v. 106, p. 6423-6446.

Keller, C.B. and Schoene, B., 2012, Statistical geochemistry reveals disruption in secular lithospheric evolution about 2.5 Gyr ago: Nature, v. 485, p. 490-493.

Keller, C.B., Schoene, B., Barboni, M., Samperton, K.M., and Husson, J.M., 2015, Volcanic-plutonic parity and the differentiation of the continental crust: Nature, v. 523, p. 301-307.

Kelley, K.A., Plank, T., Newman, S., Stolper, E.M., Grove, T.L., Parman, S., and Hauri, E.H., 2010, Mantle melting as a function of water content beneath the Mariana Arc: Journal of Petrology.

Klein, E.M. and Langmuir, C.H., 1987, Global correlations of ocean ridge basalt chemistry with axial depth and crustal thickness: Journal of Geophysical Research, v. 92, p. 80968115 .

Komiya, T., Maruyama, S., Masuda, T., Nohda, S., Hayashi, M., and Okamoto, K., 1999, Plate Tectonics at 3.8-3.7 Ga:
Field Evidence from the Isua Accretionary Complex, Southern West Greenland: The Journal of Geology, v. 107, p. 515554.

Korenaga, J., 2008, Plate tectonics, flood basalts and the evolution of Earth's oceans: Terra Nova, v. 20, p. 419-439.

Li, Z.X., Bogdanova, S.V., Collins, A.S., and Davidson, A., 2008, Assembly, configuration, and break-up history of Rodinia: A synthesis: Precambrian Research.

Liou, J.G., Tsujimori, T., Yang, J., Zhang, R.Y., and Ernst, W.G., 2014, Recycling of crustal materials through study of ultrahigh-pressure minerals in collisional orogens, ophiolites, and mantle xenoliths: A review: Journal of Asian Earth Sciences, v. 96, p. 386-420.

Martin, H., Smithies, R.H., Rapp, R., Moyen, J.F., and Champion, D., 2005, An overview of adakite, tonalitetrondhjemite-granodiorite (TTG), and sanukitoid: relationships and some implications for crustal evolution: LITHOS, v. 79, p. 1-24.

McCulloch, M.T. and Gamble, J.A., 1991, Geochemical and geodynamical constraints on subduction zone magmatism: Earth and Planetary Science Letters.

McDonough, W.F. and Sun, S.s., 1995, The composition of the Earth: Chemical Geology, v. 120, p. 223-253.

Moyen, J.F., 2010, The composite Archaean grey gneisses: Petrological significance, and evidence for a non-unique tectonic setting for Archaean crustal growth: LITHOS, v. 123, p. 21-36.

Mysen, B.O. and Boettcher, A.L., 1975, Melting of a Hydrous Mantle: I. Phase Relations of Natural Peridotite at High Pressures and Temperatures with Controlled Activities of Water, Carbon Dioxide, and Hydrogen: Journal of Petrology, v. 16, p. 520-548.

Palin, R.M. and White, R.W., 2015, Emergence of blueschists on Earth linked to secular changes in oceanic crust composition: Nature Geoscience.

Peacock, S.M., 1990, Fluid Processes in Subduction Zones: Science, v. 248, p. 329-337.

Pearce, J.A. and Cann, J.R., 1973, Tectonic setting of basic volcanic rocks determined using trace element analyses: Earth and Planetary Science Letters, v. 19, p. 290-300.

Pearce, J.A. and Peate, D.W., 1995, Tectonic Implications of the Composition of Volcanic Arc Magmas: Annual Review of Earth and Planetary Sciences, v. 23, p. 251-285.

Pearson, D.G., 1999, The age of continental roots: LITHOS, v. 48, p. 171-194.

Pease, V., Percival, J., Smithies, R.H., Stevens, G., and Van kranendonk, M.J., 2008, When did plate tectonics begin? Evidence from the orogenic record: In K.C. Condie and V. Pease (eds.), When Did Plate Tectonics Begin on Planet Earth?: Geological Society of America Special Paper 440, p. 199228, Geological Society of America.

Perfit, M.R., Gust, D.A., Bence, A.E., Arculus, R.J., and Taylor, S.R., 1980, Chemical characteristics of island-arc basalts: Implications for mantle sources: Chemical Geology, v. 30, p. 227-256. 
Plank, T., Kelley, K.A., Zimmer, M.M., Hauri, E.H., and Wallace, P.J., 2013, Why do mafic arc magmas contain 4 wt. percent water on average?: Earth and Planetary Science Letters, v. 364, p. 168-179.

Plank, T. and Langmuir, C.H., 1988, An evaluation of the global variations in the major element chemistry of arc basalts: Earth and Planetary Science Letters, v. 90, p. 349-370.

Polat, A., Hofmann, A.W., and Rosing, M.T., 2002, Boninitelike volcanic rocks in the 3.7-3.8 Ga Isua greenstone belt, West Greenland: geochemical evidence for intra-oceanic subduction zone processes in the early Earth: Chemical Geology, v. 184, p. 231-254.

Portnyagin, M., Hoernle, K., Plechov, P., Mironov, N., and Khubunaya, S., 2007, Constraints on mantle melting and composition and nature of slab components in volcanic arcs from volatiles $(\mathrm{H} 2 \mathrm{O}, \mathrm{S}, \mathrm{Cl}, \mathrm{F})$ and trace elements in melt inclusions from the Kamchatka Arc: Earth and Planetary Science Letters, v. 255, p. 53-69.

Richardson, S.H., Shirey, S.B., Harris, J., and Carlson, R.W., 2001, Archean subduction recorded by Re-Os isotopes in eclogitic sulfide inclusions in Kimberley diamonds: Earth and Planetary Science Letters, v. 191, p. 257-266.

Rudnick, R.L. and Gao, S., 2014, 4.1 Composition of the Continental Crust: In R.L. Rudnick (ed.), Treatise on Geochemistry, p. 1-51, Elsevier.

Salters, V.J.M. and Stracke, A., 2004, Composition of the depleted mantle: Geochemistry Geophysics Geosystems, v. 5.

Schmidt, M.W. and Poli, S., 2014, 4.19 Devolatilization During Subduction: In R.L. Rudnick (ed.), Treatise on Geochemistry, p. 669-701, Elsevier.

Scott, D.J., Helmstaedt, H., and Bickle, M.J., 1992, Purtuniq ophiolite, Cape Smith belt, northern Quebec, Canada: A reconstructed section of Early Proterozoic oceanic crust: Geology, v. 20, p. 173.

Shirey, S.B., Kamber, B.S., and Whitehouse, M.J., 2008, A review of the isotopic and trace element evidence for mantle and crustal processes in the Hadean and Archean: Implications for the onset of plate tectonic subduction: When did plate tectonics begin on planet Earth?: GSA Special Paper 440, p. 1-29.

Shirey, S.B. and Richardson, S.H., 2011, Start of the Wilson Cycle at 3 Ga Shown by Diamonds from Subcontinental Mantle: Science, v. 333, p. 434-436.

Sisson, T.W. and Grove, T.L., 1993, Experimental investigations of the role of $\mathrm{H} 2 \mathrm{O}$ in calc-alkaline differentiation and subduction zone magmatism: Contributions to Mineralogy and Petrology, v. 113, p. 143-166.

Sleep, N.H., 1992, Archean plate tectonics: what can be learned from continental geology?: Canadian Journal of Earth Sciences.

Smith, P.M. and Asimow, P.D., 2005, Adiabat 1ph: A new public front-end to the MELTS, pMELTS, and pHMELTS models: Geochemistry Geophysics Geosystems, v. 6, p. 1-8.

Sobolev, A.V. and Chaussidon, M., 1996, H2O concentrations in primary melts from supra-subduction zones and midocean ridges: Implications for $\mathrm{H} 2 \mathrm{O}$ storage and recycling in the mantle: Earth and Planetary Science Letters, v. 137, p. 45-55.

Stern, R.J., 2008, Modern-style plate tectonics began in Neoproterozoic time: An alternative interpretation of Earth's tectonic history: In K.C. Condie and V. Pease (eds.), When Did Plate Tectonics Begin on Planet Earth?: Geological Society of America Special Paper 440, p. 265-280, Geological Society of America.

Tatsumi, Y., Hamilton, D.L., and Nesbitt, R.W., 1986, Chemical characteristics of fluid phase released from a subducted lithosphere and origin of arc magmas: evidence from highpressure experiments and natural rocks: Journal of Volcanology and Geothermal Research, v. 29, p. 293-309.

Tsujimori, T. and Ernst, W.G., 2014, Lawsonite blueschists and lawsonite eclogites as proxies for palaeo-subduction zone processes: a review - Tsujimori - 2013 - Journal of Metamorphic Geology - Wiley Online Library: Journal of Metamorphic Geology, v. 32, p. 437-454.

Van kranendonk, M.J. and Smithies, R.H., 2007, Review: secular tectonic evolution of Archean continental crust: interplay between horizontal and vertical processes in the formation of the Pilbara Craton, Australia: Terra Nova, v. 19, p. 1-38.

Walter, M.J., 1998, Melting of garnet peridotite and the origin of komatiite and depleted lithosphere: Journal of Petrology, v. 39, p. 29-60.

Watson, S. and McKenzie, D., 1991, Melt Generation by Plumes: A Study of Hawaiian Volcanism: Journal of Petrology, v. 32, p. 501-537.

Wilson, J.F., Orpen, J.L., Bickle, M.J., Hawkesworth, C.J., Martin, A., and Nisbet, E.G., 1978, Granite-greenstone terrains of the Rhodesian Archaean craton: Nature, v. 271, p. 23-27.

Zimmer, M.M., Plank, T., Hauri, E.H., Yogodzinski, G.M., Stelling, P., Larsen, J., Singer, B.S., Jicha, B., Mandeville, C., and Nye, C.J., 2010, The Role of Water in Generating the Calc-alkaline Trend: New Volatile Data for Aleutian Magmas and a New Tholeiitic Index: Journal of Petrology, v. 51, p. 2411-2444. 

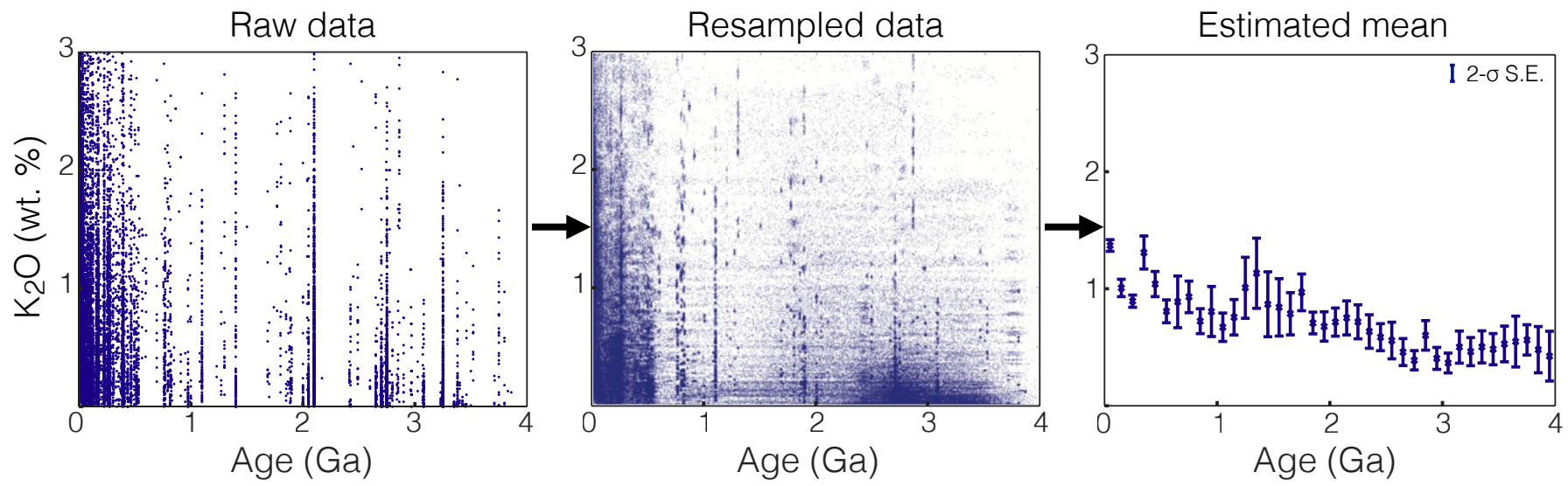

Supplementary Figure 1: Weighted bootstrap resampling method, showing raw data (left), resampled data for several bootstrap iterations with added analytical uncertainty (middle), and binned means with two-standard-error uncertainties (right). 

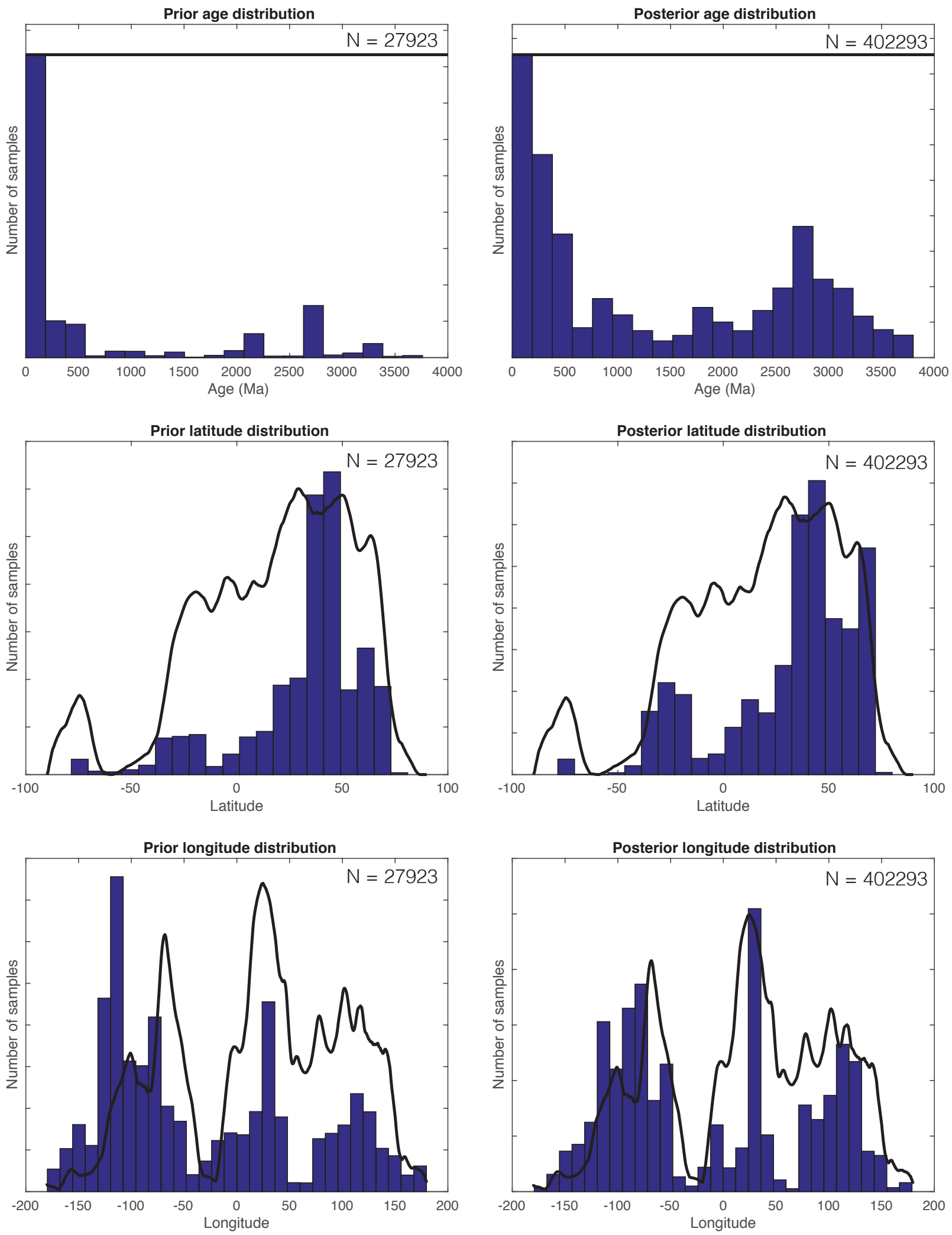

Supplementary Figure 2: Spatial and temporal sample distributions before (prior) and after bootstrap resampling (posterior). Improvement relative to the ideal geographic distribution (solid line) is limited by imperfect exposure (e.g. pervasive rainforest cover around $0^{\circ}$ latitude, and complete ice cover near $-90^{\circ}$ latitude), by the mean resampling probability, and by the tradeoff between spatial and temporal evenness. Nonetheless, improvement is visible in all cases. 

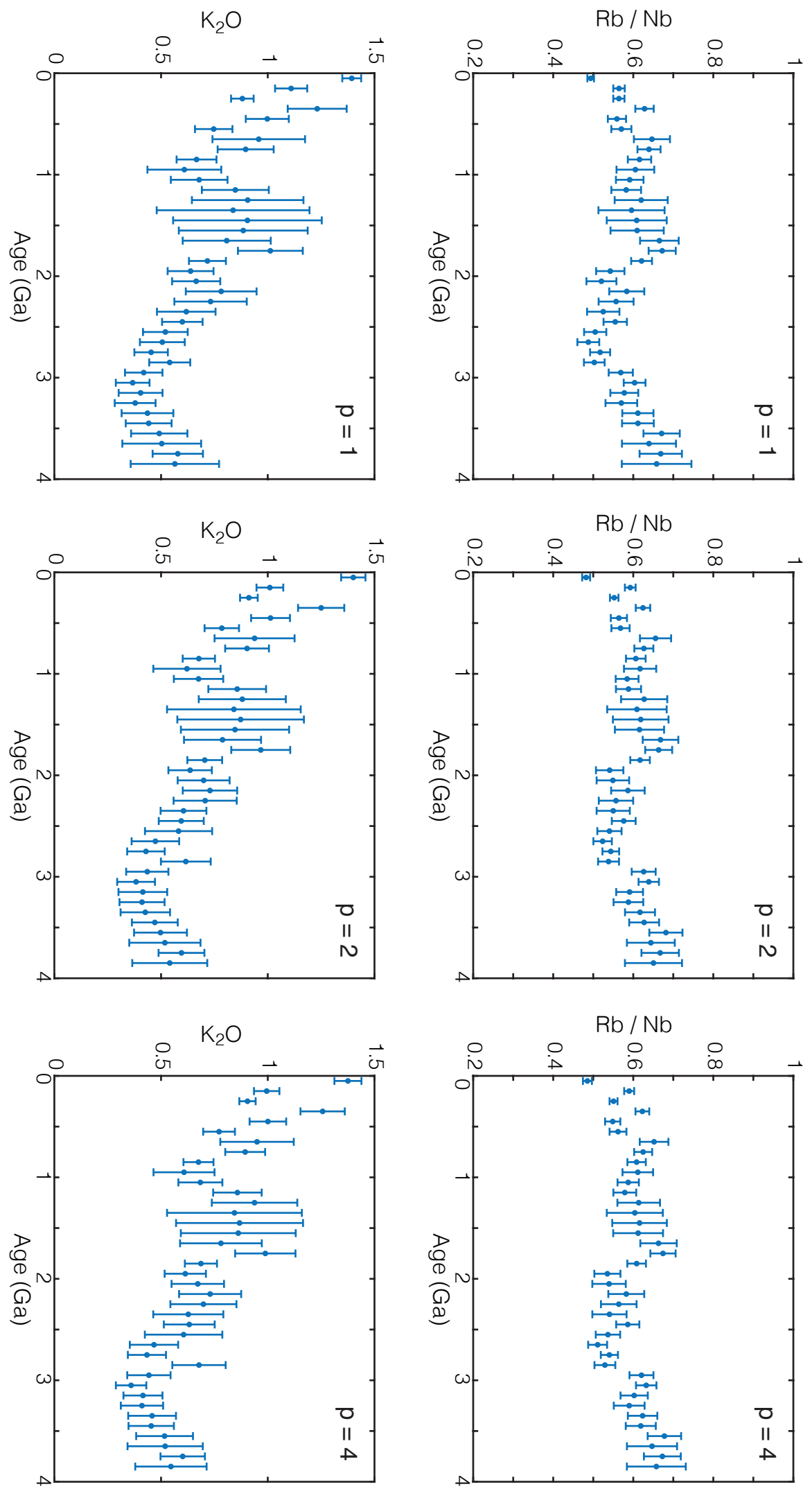

Supplementary Figure 3: Sensitivity of weighted resampling results to the choice of weighting exponent. Any systematic variation in temporal geochemical trends in response to changes in the weighting exponent is minor, and is typically not visible at the scale of the standard error. 


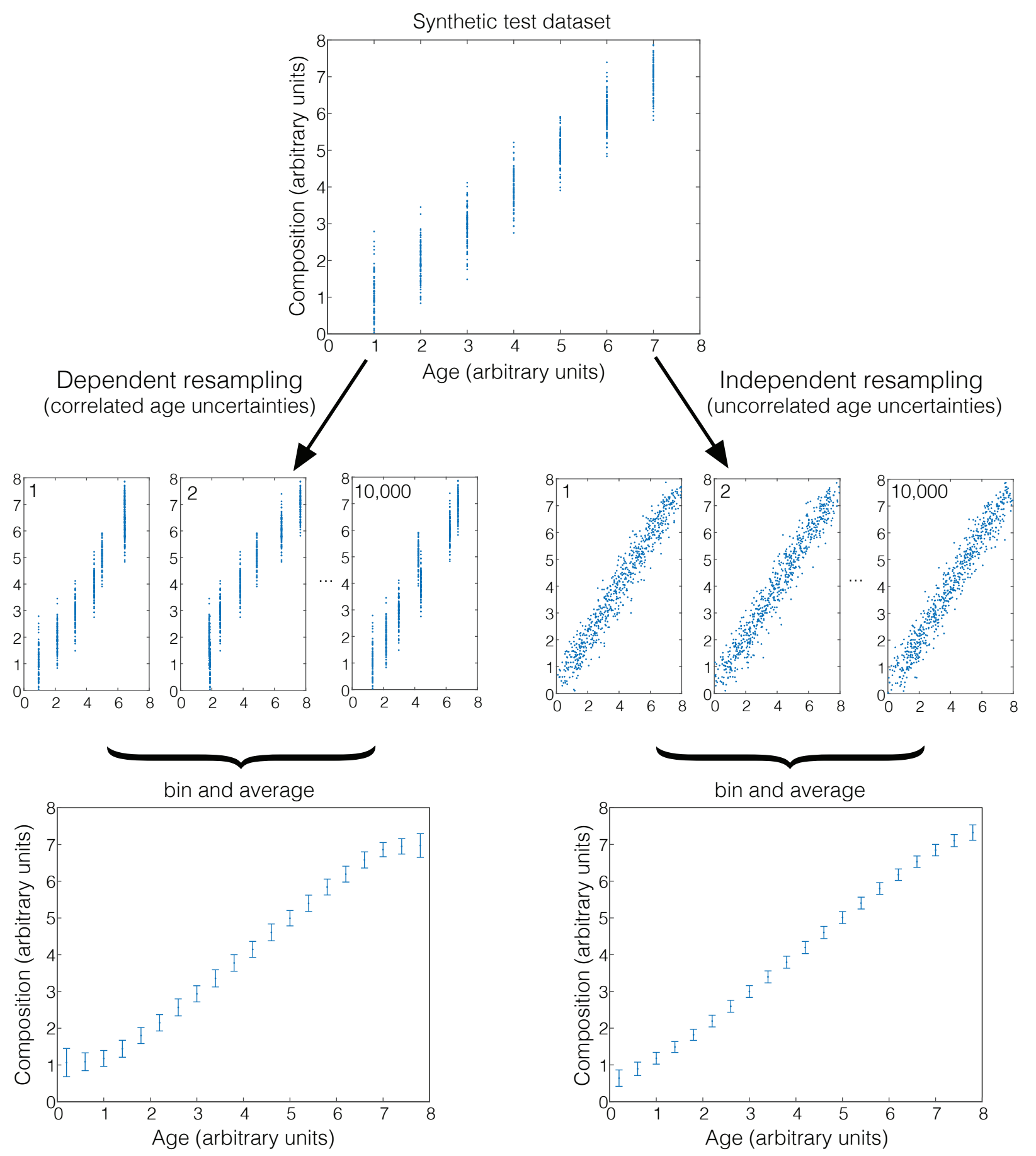

Supplementary Figure 4: Sensitivity of weighted resampling results to correlated versus uncorrelated age uncertainty. Despite the clearly visible differences in the form of the individual bootstrap sample sets, the difference in the binned mean and standard error are minor even in the extreme case of fully dependent (correlated) versus fully independent (uncorrelated) age uncertainties. 

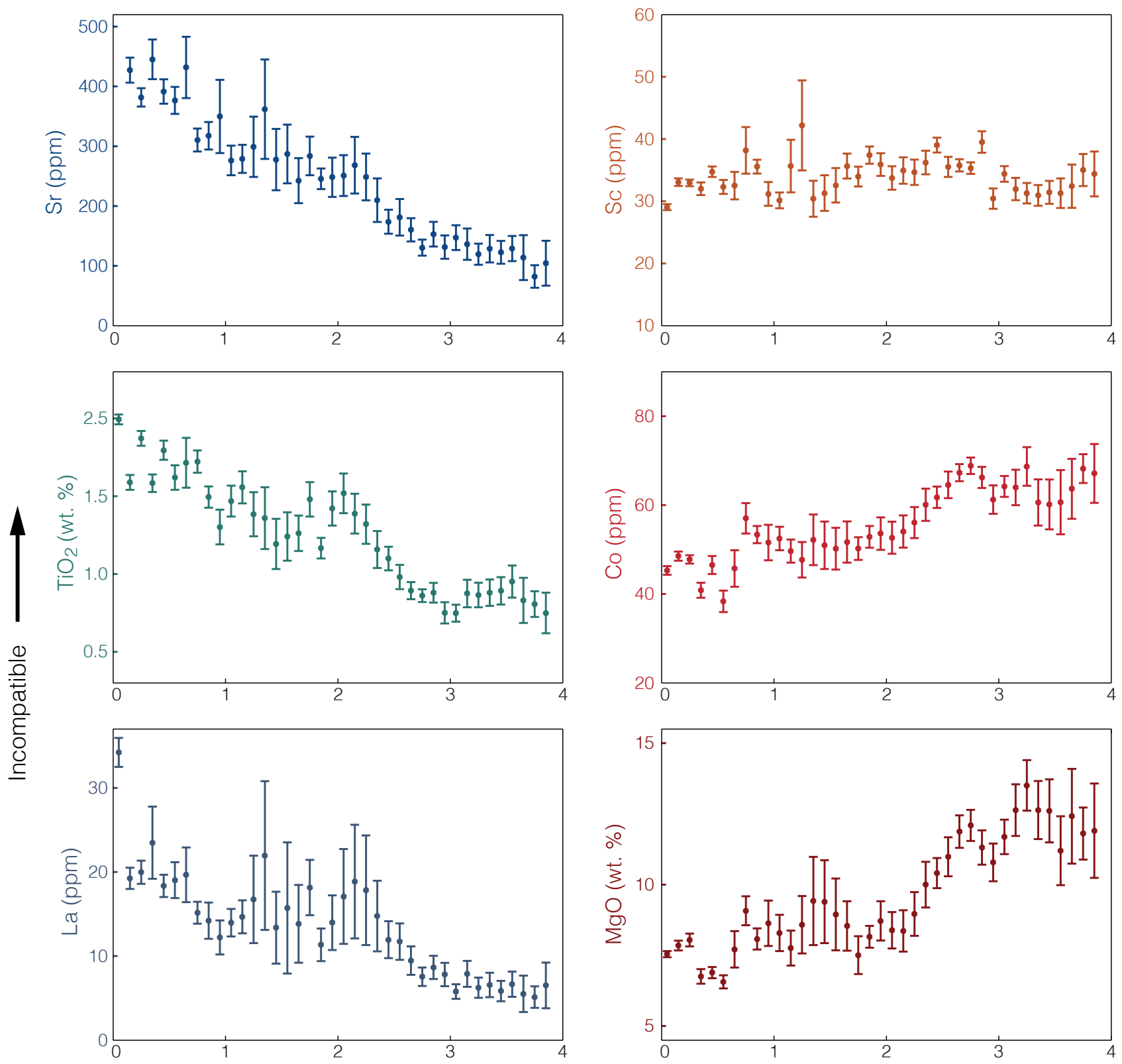

$\frac{0}{0}$
$\frac{0}{\overline{0}}$
$\frac{\Omega}{E}$
$\frac{1}{0}$
0
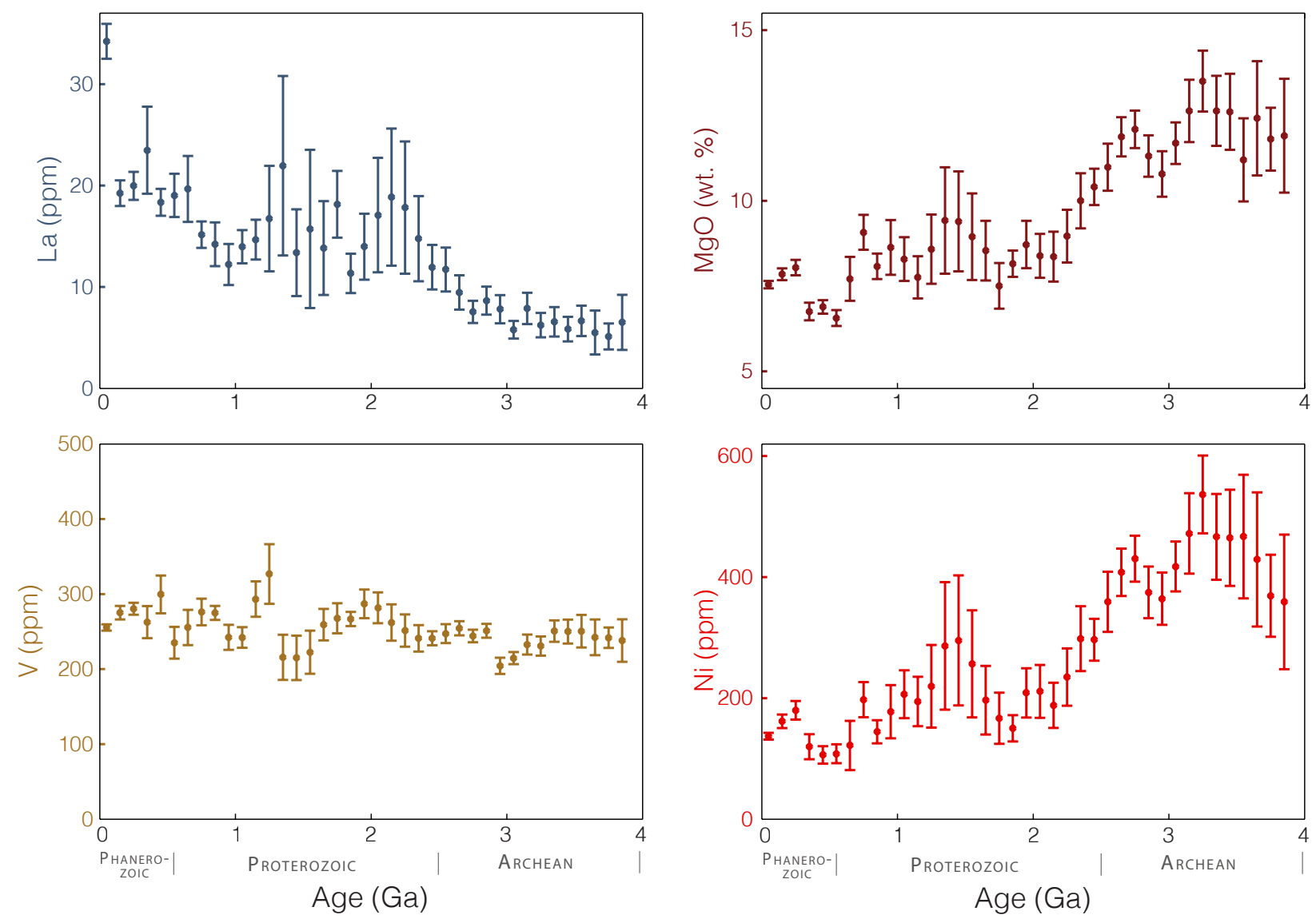

Supplementary Figure 5: Extended systematic comparison of basaltic compatible and incompatible element abundance trends, sorted by relative compatibility. 

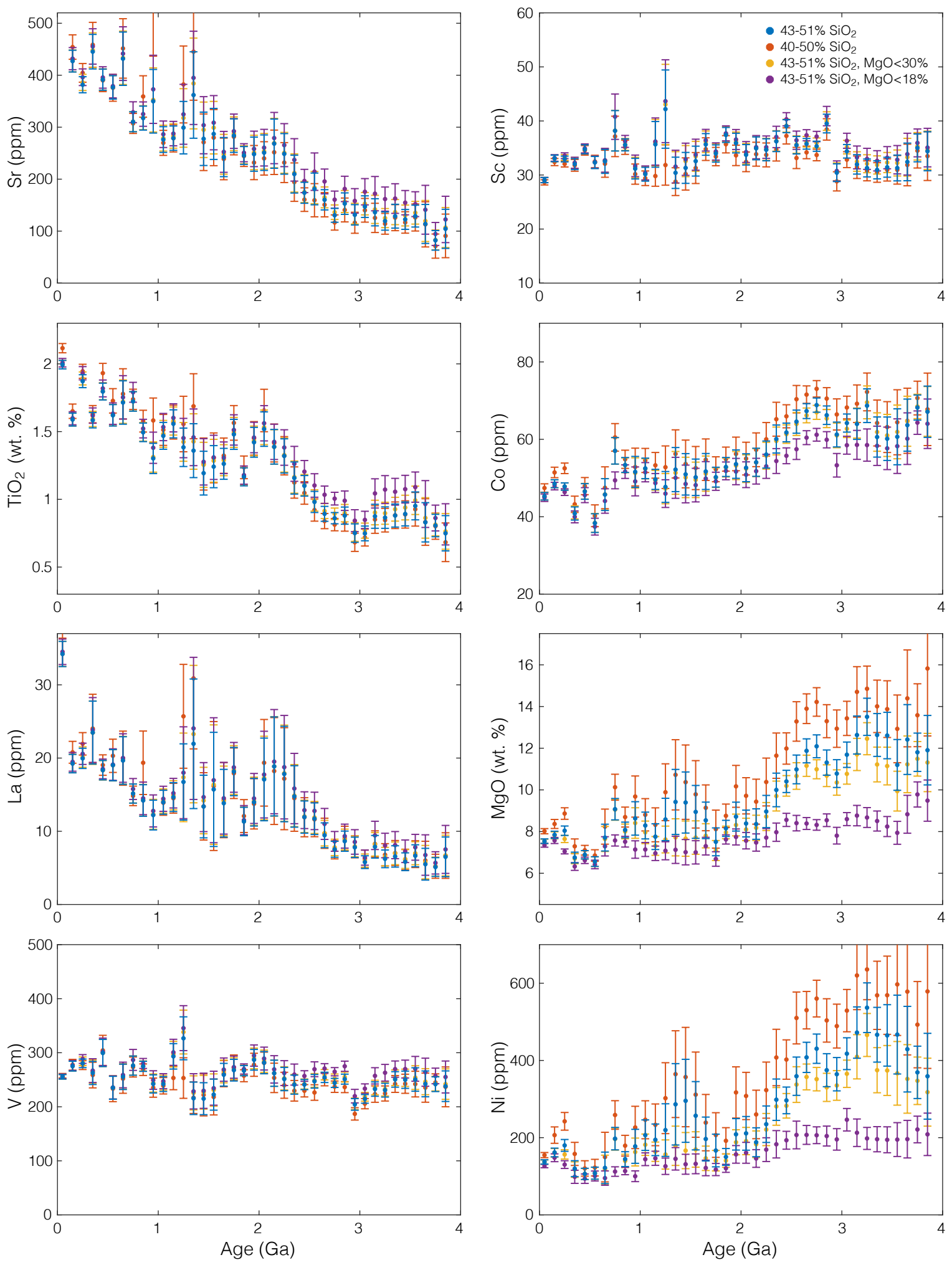

Supplementary Figure 6: Comparison of compatible and incompatible element trends for several geochemical definitions of what might reasonably be considered to include mafic mantle-derived magmas: $43-51 \% \mathrm{SiO}_{2}$ (blue), $40-50 \% \mathrm{SiO}_{2}(\mathrm{red}), 43-51 \% \mathrm{SiO}_{2}$ with $\mathrm{MgO}<30 \%$ (yellow), and $43-51 \% \mathrm{SiO}_{2}$ with $\mathrm{MgO}<18 \%$ (purple). All variations considered have little to no effect for all but the most compatible elements. Excluding samples with more than $30 \% \mathrm{MgO}$ from the $43-51 \%$ silica range has little effect even for $\mathrm{MgO}$, suggesting that ultramafic cumulates are already largely excluded from this silica range (shifting the minimum $\mathrm{SiO}_{2}$ content to $40 \%$ has a substantially larger effect). Excluding komatiites by rejecting samples with more than $18 \% \mathrm{MgO}$ has by far the largest impact on the highly compatible element trends - but komatiites should be not excluded if one wishes to consider all real mantle-derived magmas preserved in the continental crust. 
Preprint - Plate tectonics and continental basaltic Geochemistry throughout Earth history

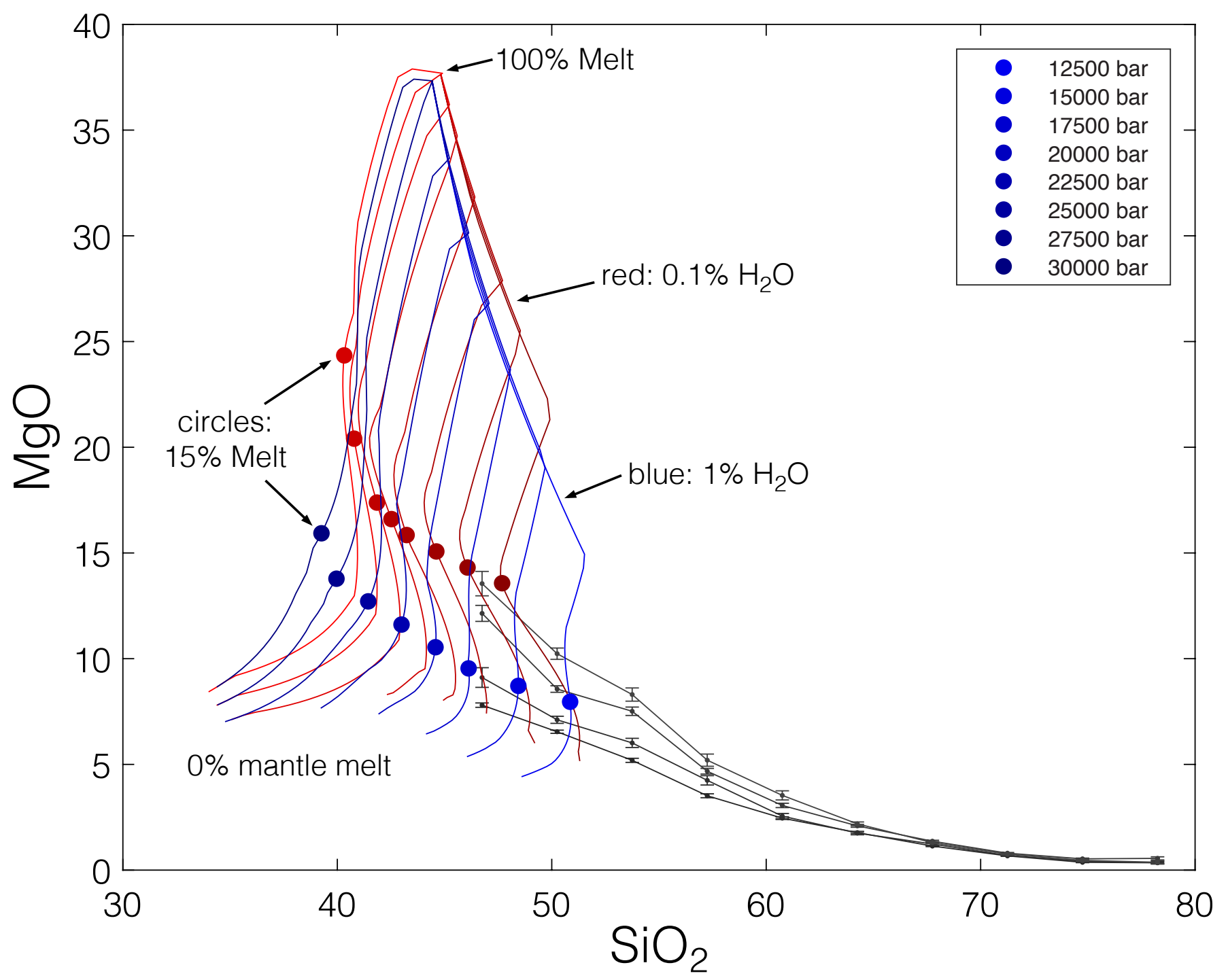

Supplementary Figure 7: Example of exploratory MELTS simulations used to construct mantle melting extent and melting pressure direction schematics in Figure 3. While silica content does vary during mantle melting, this variation is not systematic $\left(\mathrm{SiO}_{2}\right.$ may either increase or decrease depending on melting conditions) and is minimal compared the variations in magma $\mathrm{MgO}$ over the same range of mantle melting extents $\left(\sim 10 \%\right.$ relative variation in $\mathrm{SiO}_{2}$ between $0 \%$ melt and $100 \%$ melt versus variation by a factor of 7 for $\mathrm{MgO}$ over the same range). 

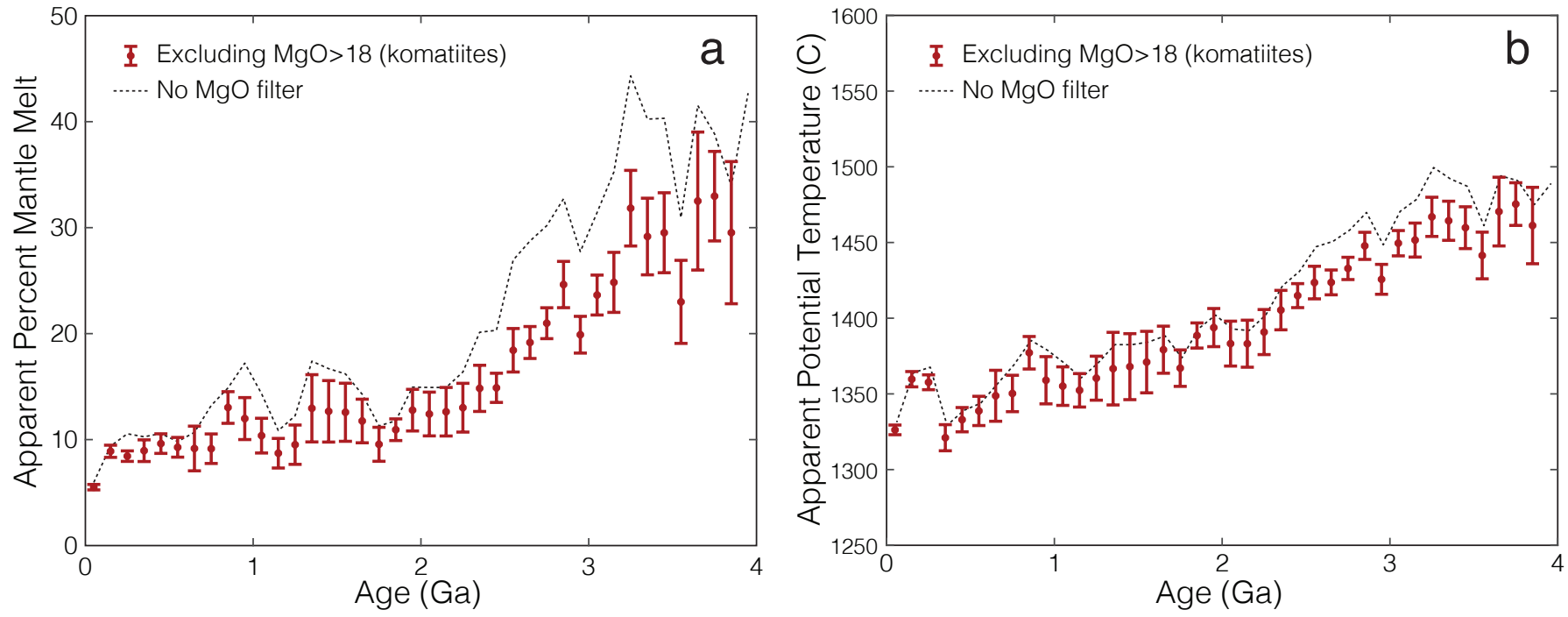

Supplementary Figure 8: Apparent percent melt (a) and potential temperature (b) calculated as in Figure 4, but rejecting all wholerock analyses with more than $18 \mathrm{wt} . \% \mathrm{MgO}$ (i.e., komatiites). Despite the significant impact of excluding Archean komatiites on average $\mathrm{MgO}$ (e.g., Supplementary Figure 6), the impact on estimated melting extent and melting temperature is modest, not far exceeding internal standard error even in the Archean.
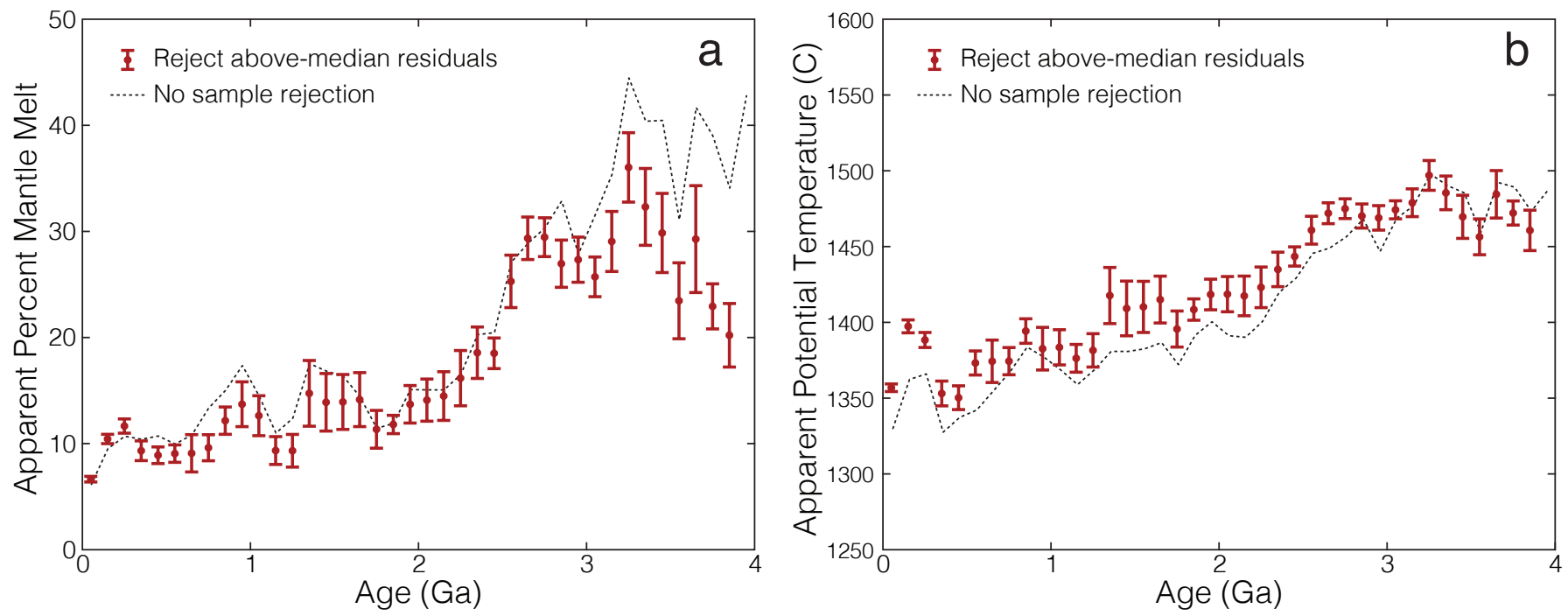

Supplementary Figure 9: Apparent percent melt (a) and potential temperature (b) calculated as in Figure 4, but rejecting all wholerock analyses with least-squared residuals above the median residual. Variations in the inversion results are minor, generally within mutual two-standard-error uncertainty (c.f. Figure 4). 

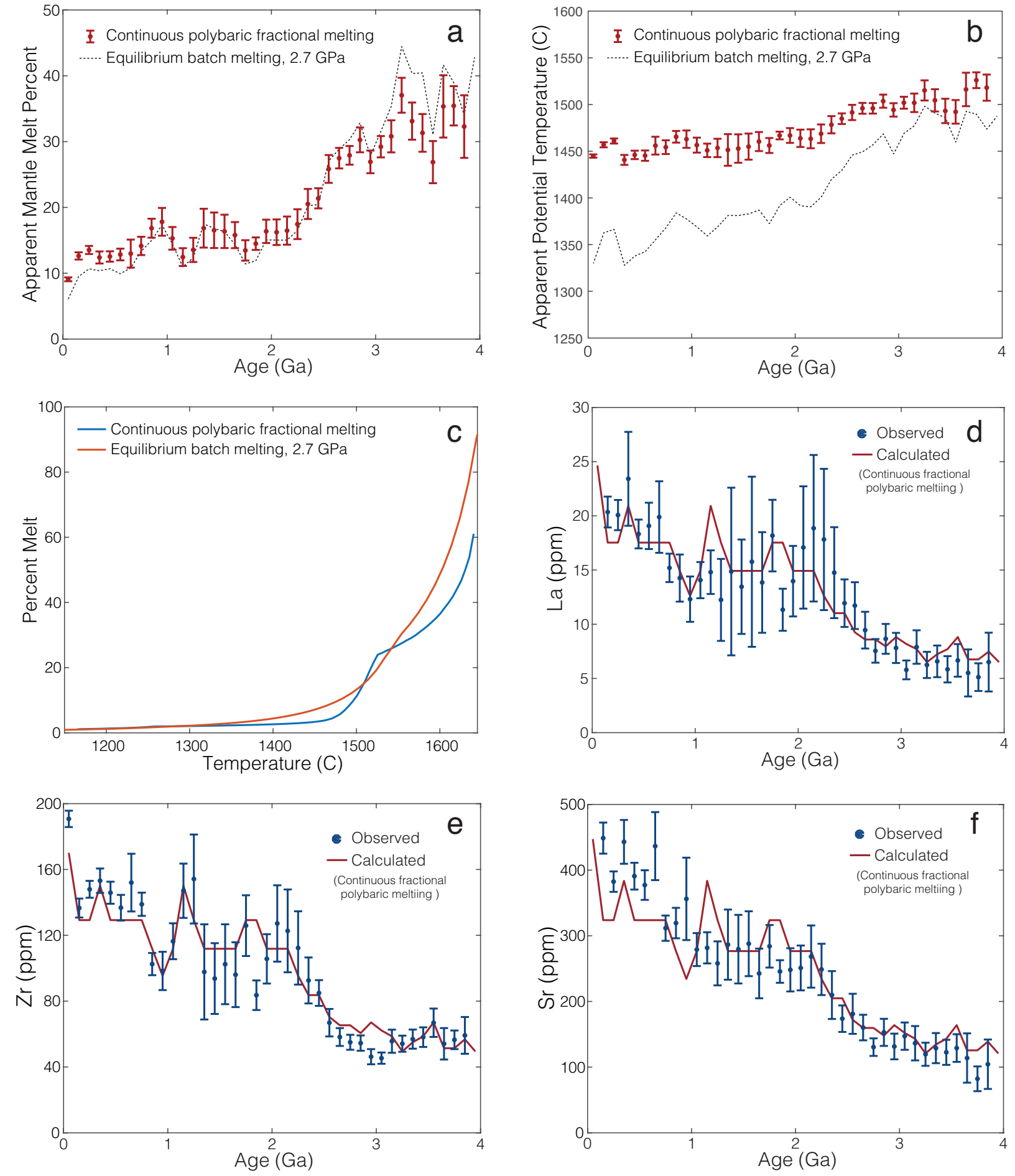

Supplementary Figure 10: Percent melt and temperature estimates over the past $4 \mathrm{Gyr}(\mathrm{a}, \mathrm{b})$, the nonlinear variation of melting extent as a function of temperature (c), and trace element model results for the past $4 \mathrm{Gyr}$ (d-f) in the case of continuous polybaric fractional melting rather than simple equilibrium batch melting, as discussed in Appendix B 

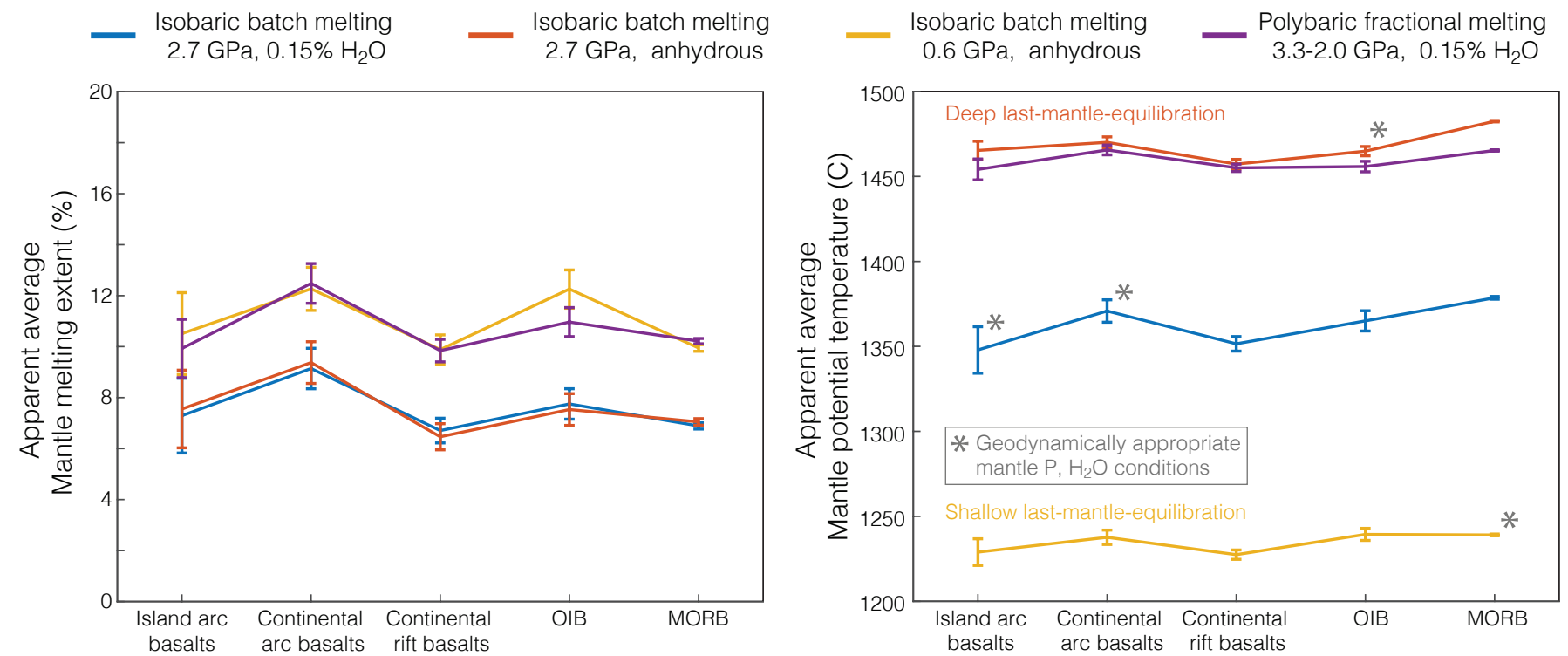

Supplementary Figure 11: Estimated mantle melting extent and potential temperature for a range of modern basalt types as estimated using a range of MELTS models and model parameters, including continuous and batch melting at multiple pressures and magma water contents, as discussed in Appendix B. Melting inversions are based on the primitive mantle starting composition of McDonough and Sun (1995), except those for MORB, which rely on the depleted mantle composition of Salters and Stracke (2004). Asterisks indicate $\mathrm{P}, \mathrm{H}_{2} \mathrm{O}$ conditions most applicable for each geodynamic setting. Continuous polybaric melting displays anomalously hot mantle potential temperatures due to unrealistic early dehydration in the open-system continuous melting model. 